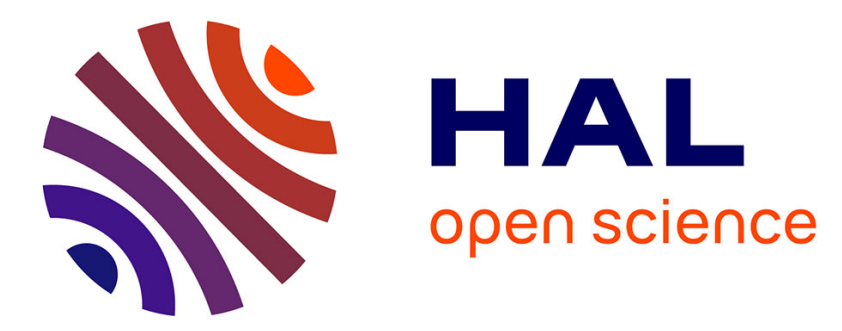

\title{
Gesture Analysis and Organizational Research: The Development and Application of a Protocol for Naturalistic Settings
}

Jean Clarke, Nicholas Llewellyn, Joep P. Cornelissen, Rowena Viney

\section{- To cite this version:}

Jean Clarke, Nicholas Llewellyn, Joep P. Cornelissen, Rowena Viney. Gesture Analysis and Organizational Research: The Development and Application of a Protocol for Naturalistic Settings. Organizational Research Methods, 2019, FORTH. hal-02299462

\section{HAL Id: hal-02299462 \\ https://hal.science/hal-02299462}

Submitted on 27 Sep 2019

HAL is a multi-disciplinary open access archive for the deposit and dissemination of scientific research documents, whether they are published or not. The documents may come from teaching and research institutions in France or abroad, or from public or private research centers.
L'archive ouverte pluridisciplinaire HAL, est destinée au dépôt et à la diffusion de documents scientifiques de niveau recherche, publiés ou non, émanant des établissements d'enseignement et de recherche français ou étrangers, des laboratoires publics ou privés. 


\title{
Gesture Analysis and Organizational Research: The Development and Application of a Protocol for Naturalistic Settings
}

Organizational Research Methods I-32

(C) The Author(s) 2019 Article reuse guidelines: sagepub.com/journals-permissions DOI: | 0.1 | 777/1094428|19877450 journals.sagepub.com/home/orm

@SAGE

\author{
Jean S. Clarke', Nicholas Llewellyn ${ }^{2}$, Joep Cornelissen ${ }^{3}$, \\ and Rowena Viney ${ }^{4}$
}

\begin{abstract}
Gestures are an underresearched but potentially significant aspect of organizational conduct that is relevant to researchers across a range of theoretical and empirical domains. In engaging the crossdisciplinary field of gesture studies, we develop and apply a protocol for analyzing gestures produced in naturalistic settings during ongoing streams of talk and embodied activity. Analyzing video recordings of entrepreneurial investor pitches, we work through this protocol and demonstrate its usefulness. While doing so, we also explore methodological tensions in gesture studies and draw out methodological arguments as they relate to the analysis of these fleeting and often intricate bodily movements. The article contributes a generally applicable protocol for the analysis of gestures in naturalistic settings, and it assesses the methodological implications of this protocol both for research on entrepreneurship and new venture creation and management and organization research more generally.
\end{abstract}

\section{Keywords}

gestures, naturalistic settings, investor pitches, organizational presentation, conversation analysis, cognitive linguistics, multimodality

\section{Introduction}

Gestures are an underresearched but potentially significant aspect of organizational conduct relevant to researchers across a range of domains, such as organizational communication (Jablin \& Putnam,

\footnotetext{
'Emlyon Business School, Ecully, France

${ }^{2}$ Warwick Business School, Coventry, UK

${ }^{3}$ Rotterdam School of Management, Rotterdam, Netherlands

${ }^{4}$ University College London, London, UK

Corresponding Author:

Jean Clarke, Emlyon Business School, 23 Avenue Guy de Collongue, Ecully, 69134, France.

Email: clarke@em-lyon.com
} 
2000), multimodality (Iedema, 2007; Kress \& van Leeuwen, 2001), visual studies (Bell, 2012; Bell, Warren, \& Schroeder, 2014), metaphor analysis (Cornelissen, 2005; Cornelissen \& Clarke 2010), and conversation analysis (Llewellyn \& Hindmarsh 2010), and for those interested in empirical settings in which gestures often occur, such as keynote lectures (Wenzel \& Koch, 2018), strategy briefings (Gylfe, Franck, LeBaron, \& Mantere, 2016), and investor pitches (Clarke, Cornelissen, \& Healey, 2019). In organizational research, while the moving bodies of speakers have been drawn into analytic accounts (see Hindmarsh \& Pilnick, 2007; LeBaron, Christianson, Garrett, \& Ilan, 2016; Llewellyn, 2014), gestures, defined as movements of hands and arms that co-occur with speech, as a specific subset of embodied conduct have been largely overlooked. This is a significant oversight because gestures may be tightly coupled with the messages and actions that speakers project in natural settings (Kaschak et al., 2005; Kendon, 1972; McNeill, 1985). Gestures may elaborate on what is said or add entirely new aspects not present in speech. In this sense, gestures have been said to play "an integral part of an individual's communicative effort" (Kendon, 1983, p. 27).

Gestures have not been pursued in depth in organizational research perhaps due to certain barriers to the development of such work. Researchers wishing to investigate gestures in naturalistic settings confront a variety of daunting methodological questions and challenges. While there has been some work recently in the organizational domain in relation to understanding gestures through experimental means, where conditions are orchestrated and controlled by the researcher (Congdon, Novack, \& Goldin-Meadow, 2018), there is little specific guidance on analyzing gestures "in the wild," namely, the natural interactions and communications that routinely happen in organizations in the form of meetings, presentations, handovers, discussions, and so on (Streeck, Goodwin, \& LeBaron, 2011). The cross-disciplinary field of gesture studies is also a highly specialized domain that draws on technical frameworks that may be unfamiliar to organizational researchers. For those new to the area, there is little guidance on basic questions regarding how to record and describe gestures, how to represent gestures in research papers, which gestural forms commonly run alongside speech, and which research questions can be addressed by analyzing gestures. The present article addresses these concerns. It introduces the field of gesture studies and empirically illustrates a protocol for gesture analysis in naturalistic settings. In elaborating the protocol, we produce a gesture analysis of a single original data set consisting of 54 video recordings of investor pitches that we use to illustrate the value of the protocol, and in doing so, we highlight the role of theoretical assumptions in gesture research.

The article is organized as follows. First, we introduce the field of gesture studies and frame a central tension in the field, namely, between action-oriented approaches that analyze what gestures $d o$ and cognitive approaches that analyze how gestures offer insight into how people are "thinking." Literature on investor pitches is then reviewed, and we argue they present an interesting context from which to explore the kinds of contribution gesture studies might make to research on organizational communication. A six-step protocol for gesture research in natural field settings is then introduced and elaborated on through the analysis of the investor pitch data set. Here, we aim to contribute a protocol for naturalistic settings, in contrast to recent research that has focused on manipulating gestures in experimental conditions and on using experimental methods (Clarke et al., 2019; Congdon et al., 2018). Through this analysis, we reveal what we call an entrepreneurial gesture code, or a recurrent set of six gestural forms through which entrepreneurs address matters important to them, including "expansion," "growth," the establishment of "new combinations," and so on. The discussion and conclusion evaluate the protocol, and we consider how gesture analysis might enhance studies of entrepreneurship and new venture creation and organizational and management research more generally. 


\section{Gesture Studies: A Brief Introduction}

Gesture studies is a multidisciplinary field that cuts across linguistics and the social and cognitive sciences, and it is based on a shared set of conjectures: Gestures communicate, have a distinctive character that separates them from general body movements, and conform to recurrent types. These points are briefly discussed in the following before exploring a central tension within this multidisciplinary field.

Do gestures play a communicative role? In provocatively challenging this view, Rimé and Schiaratura (1991) argue that they do not, suggesting that interlocutors typically fail to notice gestures, that gestures make no difference to comprehension, and that recipients often fail to link gestures with lexical content. Gestures, they argue, are not communicative. The field of gesture studies has however assembled compelling evidence against this argument from studies informed by different methodological traditions. A series of classic experimental studies (see Kendon, 1994, pp. 177-187, for a full account) show the importance of gestures in communication. For example, Berger and Popelka (1971) demonstrated that recipients develop more accurate understandings when utterances are produced alongside emblems or quotable gestures (gestures that can be used as substitutes for words, e.g., the peace sign). In another experiment, Rogers (1978) played video recordings of people speaking and gesturing to subjects under three conditions: (a) with sound and vision, (b) with sound and vision but where the mouth and face of the speaker was blurred, and (c) with only sound. Visual access to the speaker even when the mouth and face were blurred was associated with improved comprehension for listeners. Drawing on very different methodological resources, early microanalytical work in sociology (C. Goodwin, 1986; Heath, 1986) recovered how people allow their conduct to be guided in light of interlocutors' gestural work, for example, when people point or nod and successfully redirect the visual attention of a companion without any verbal content.

Second, there is widespread agreement that gestures have defined characteristics that differentiate them from more general body movements such as fidgeting, postural shifts, or self-manipulations (Bressem \& Ladewig, 2011; Kendon, 1996). Gestures are characterized as distinctive phases of activity that are marked and separate. Schegloff (1984) called them excursions, or movements that shift from a "rest position" through a preparation phase to the main gesticulation or "stroke" phase, which may be "held" before returning to the rest position via a "retraction" of some kind (Kendon, 1980, p. 212). As such, gestures have a "peak" structure (Kendon, 1980) or a semiotic core or central business that is often, though not always, bounded by a clear beginning and end. Moreover, gestures often display a kind of symmetry (Kendon, 1996); when recordings are played backwards and forwards, the gesture looks similar.

While gestures are used in a range of communicative settings for different communicative purposes (Ekman \& Friesen, 1969), researchers have identified particular patterns through which people display gestures. A number of classifications for these patterns have been developed (Cassell, 1998; De Ruiter, 2000; Efron, 1941; Kendon, 2015; McNeill, 1992). While each of these classifications is slightly different, they overlap a good deal, and a shared vocabulary has been emerging. Deictic gestures point to either real or imaginary persons or objects; emblems or emblematic gestures, sometimes called symbolic gestures, convey verbal meaning without words (e.g., a thumbs up in Western culture). What McNeill (1992, p. 76) called iconic gestures, sometimes called literal reproductive or pictographs, depict the semantic content of speech in a literal fashion, namely, a person talking about breaking a tablet in two might motion with his or her hands to mimic breaking something apart. Like iconics, metaphoric gestures depict imagery present in speech, but unlike iconic gestures, the verbal content does not have a material form, namely, a person commenting on the length of a meeting might accompany this comment with a hand-rolling motion (Cassell, 1998), depicting something that has gone on and on. Beat gestures (Cassell, 1998), sometimes called 
parsing gestures (Streeck, 2008a), do not illustrate the content of speech but work to divide or "parse" the speech. Kendon (2015) defined three categories of gestures: Pragmatic gestures reveal the action being performed, deictic gestures direct the attention of others, and representational gestures conjure up objects, persons, spatial relations, and so on that may be literal or metaphoric.

Gesture studies has developed as an interdisciplinary field based on these shared conjectures. While the field is pluralistic, Kendon (2017) argued that the central tendency of contemporary gesture studies is to focus on psychological processes. He argued that "for the most part, the hand movements that people make when they speak have been studied as representations of the substantive or propositional content of the utterance, seen as providing clues about the mental or cognitive processes governing speaking" (p. 157).

Links between psychology and gestures can be traced to pioneering 19th-century studies such as Tylor's (1865) Researches Into the Early History of Mankind, which devotes three chapters to gestures. In the 20th century, Kendon (2007) noted a series of developments that framed and animated the psychology of gestures. For example, a search for "language origins" (Hockett \& Ascher, 1964) led scholars to systematically codify the design features of spoken language such that they could be compared to other sign systems in which other actors engaged; this led, for example, to the analysis of great apes' gestural expressions, which were shown to far exceed their vocal capacities. The cognitive turn in linguistics and Chomsky's notion of a hardwired "language acquisition device" led researchers to video record the utterances of very young children, data that revealed the importance of semantic actions of any type, including gestures exchanged between mothers and infants (Bates, Benigni, Bretherton, Camaioni, \& Volterra, 1979). Alongside the work of Bates et al. (1979), which linked speech and gestures as manifestations of a general process, came David McNeill's (1985) influential argument that gestures share with speech a common "computational stage" and thus form part of the same psychological structure (McNeill, 1985, p. 350). In focusing on psychological activities occurring during speech, he challenged a suite of previously secure distinctions, for example, between what is (and is not) "linguistic" (McNeill, 1985, p. 350).

With the protocol that we develop in the present article, we engage the psychology of gestures by drawing on cognitive linguistics (see Lakoff, 1987; Langacker, 1987; Talmy, 2000), a framework employed by McNeill (see McNeill 1992; McNeill \& Levy 1982) and others within the field (see Langacker, 2008). Cognitive linguistics, an approach to the analysis of natural language originating in the late 1970s, is concerned with how language forms our thoughts by allowing us to organize, process, and convey information. Specifically, we draw on the foundational work of Lakoff and Johnson (1980, 1999), who developed conceptual metaphor theory (CMT). A basic tenet of CMT states that the pervasive use of verbal metaphor reflects the fact that people think metaphorically and that such metaphors are manifested in speech, gestures, body movements, and visuals (Cienki \& Müller, 2008; Forceville \& Urios-Aparisi, 2009). According to Lakoff and Johnson's (1980, 1999) theory, language interacts with the body. Conceptual metaphor is "a natural part of human thought ... [and] which metaphors we have and what they mean depend on the nature of our bodies, our interactions in the physical environment" (Lakoff \& Johnson 1980, p. 247). Metaphors link two conceptual domains, the source domain and the target domain. The source domain is the conceptual domain from which we draw metaphorical expressions based on concrete, embodied, and easily understood concepts. The target domain tends to be abstract and takes its structure from the source domain through the metaphorical link.

Based on this argument, evidence of how people think of one domain in terms of another should appear in gestures; "if speakers are thinking in terms of imagery from the metaphoric source domain, we might expect to see some representation of that imagery in their gestures" (Cienki, 2016, p. 604). The enactment of metaphors in gestures can therefore serve as strong confirmation of the active use of a metaphor in an individual's language and thoughts and supports "the dynamic creation, and 
recreation, of metaphoric thought in the bodily act of online communication" (Gibbs, 2008, p. 292; Casasanto \& Bottini, 2014; Cienki, 1998, 2005, 2013; Muüller, 2008; Sweetser, 1998).

While cognitive linguistics is especially good at understanding metaphoric (McNeill, 1992) or representational (Kendon, 2017) gestures, we argue for the need to supplement this predominant focus with microanalytic sensibility (C. Goodwin, 2000a; Streeck, 2008b) grounded at the interactional level to recover the social and interactional functions of pragmatic and deictic gestures (Kendon, 2017). In noting that the field of gesture studies has tended to privilege psychological processes, Kendon (2017) sounded a note of caution by reminding us that "speaking is also a form of social action [italics added], however, and gestures play an important role in this" (p. 157). As well as providing clues on how people are thinking, gestures can also be used to do things. Through the protocol we develop, we therefore draw on methodological resources from the microanalytic approach (see Streeck, 2008b), which itself engages and draws on conversation analysis (Sacks, Schegloff, \& Jefferson, 1974) to recover the character of pragmatic and deictic gestures.

Conversation analysis (CA) was first developed in the 1960s (see Sacks, 1992; Sacks et al., 1974; Schegloff, 1968) and is now an extensive international discipline focusing on the organization of body movements, gestures, and speech. CA starts from the idea that people "recognize the shape and character of what is occurring" (C. Goodwin, 2000a, p. 1491) not from shared mental models but from the interplay between talk and embodied activity within sequences of prior and subsequent actions. From a CA perspective, action is investigated in terms of "contextual configurations," meaning that domains of phenomena that are often considered so distinct they are treated by separate academic disciplines, such as language, the body, and material structures, in CA are analyzed together "as integrated components of a common process for the social production of meaning and action" (C. Goodwin, 2000a, p. 1490).

Conversation analysis was influential in generating key "observational studies" of gestures not least because gestures form a domain in which speech, materiality, and the body interact so clearly (see C. Goodwin, 2000a; M. H. Goodwin, 1980; Heath, 1986; Streeck, 1993; Streeck \& Hartge, 1992). CA approaches to gestures (e.g., C. Goodwin, 1979, 1986, 2000a, 2003; M. H. Goodwin \& Goodwin, 1986; Hayashi, 2003; Heath, 1986; Schegloff, 1984; Sidnell, 2005; Streeck, 1993, 1994) have demonstrated how gestures play an important role in interactional organization or how "speakers parcel out between speech and gesture what they project in their utterance in ways that vary appropriately in relation to the communicative circumstances in which they find themselves" (Kendon, 1994, p. 188). In an analysis of medical interviews, for example, Heath (2002, p. 601) showed how gestures "demarcate the position, the scale ... and the character of the suffering. They enliven, if only momentarily, different parts of the body and provide a dramatic display of the symptoms and suffering incurred by the patient." Gestures have been shown to serve as cues relevant for the organization of interactions, such as turn-taking (M. H. Goodwin \& Goodwin, 1986; Schegloff, 1984; Streeck \& Hartge, 1992), spontaneous forms of collaboration (Hindmarsh \& Heath, 2000), eliciting responses (Streeck, 1994), and so on. Such work has shown gestures to serve as much more than a "visual mirror of lexical content," displaying aspects of meaning not present in the accompanying stream of speech (C. Goodwin, 2000a, p. 1498).

In summary, gestures studies is a mature, internationally recognized, multidisciplinary field researching a range of diverse issues such as first- and second-language acquisition (Ozcaliskan \& Goldin-Meadow, 2005; Tellier, 2008), narratives and gestures (Jacobs \& Garnham, 2007), sign languages (Corina \& Gutierrez, 2016; Green, 2017), conditions such as aphasia (C. Goodwin, 2000b) and language impairment (Sanjeevan, Mainela-Arnold, Alibali, \& Evans, 2016), gesture recognition (by humans and computers; Cassell, 1998), and robotics (Ng-Thow-Hing, Luo, \& Okita, 2010). It is also theoretically pluralistic, with diverse frameworks ranging from semiotics (Bouissac, 2008), ethnomethodology (C. Goodwin, 2000a), deconstruction (Montredon et al., 2008), and microanalysis (Streeck, 2008b) to cultural studies (Quinn, 2008) and cognitive 
Table 1. Overview of Gesture Types.

\begin{tabular}{|c|c|c|c|}
\hline Gesture Type & Communicative Roles & $\begin{array}{l}\text { Theoretical and } \\
\text { Methodological } \\
\text { Resources }\end{array}$ & Guiding Assumptions \\
\hline $\begin{array}{l}\text { Representational } \\
\text { (iconic or } \\
\text { metaphonic) }\end{array}$ & $\begin{array}{l}\text { Depict objects, persons, spatial } \\
\text { relations, and so on, which may be } \\
\text { literal or metaphonic. }\end{array}$ & Cognitive linguistics & $\begin{array}{l}\text { Gestures reveal metaphors } \\
\text { that underpin situated } \\
\text { cognition; } \\
\text { Requirement to video } \\
\text { record the speaker } \\
\text { Gestures are resources for } \\
\text { the accomplishment of } \\
\text { concerted actions; }\end{array}$ \\
\hline $\begin{array}{l}\text { Pragmatic } \\
\text { Deictic }\end{array}$ & $\begin{array}{l}\text { Reveal the action being performed } \\
\text { Direct the attention of others }\end{array}$ & Conversation analysis & $\begin{array}{l}\text { Requirement to video } \\
\text { record the speaker and } \\
\text { recipient }\end{array}$ \\
\hline
\end{tabular}

linguistics (McNeill, 1992). In building our protocol, we have thus made choices regarding which theoretical and methodological resource to engage. To develop a comprehensive but practically useful protocol for naturalistic settings, we have used mainstream approaches that grant us access to representational, pragmatic, and deictic gestures (Kendon, 2017; see Table 1 for an overview of these gesture types, their communicative roles, theoretical and methodological resources, and guiding assumptions). The relations between these approaches and the extent of their compatibility are addressed later in the article.

\section{Understanding Entrepreneurial Pitches}

We develop and demonstrate our protocol for the analysis of gestures in naturalistic settings by examining gestures within the context of investor pitches where entrepreneurs are given a limited amount of time to "sell" their business propositions to an audience of potential investors (Clarke et al., 2019). The resulting protocol is not specific to entrepreneurial contexts and is relevant for the analysis of gestures in a wide range of organizational settings where interpersonal or group communication, understanding, or persuasion is important.

The acquisition of investment is a critical step for many entrepreneurs in the early stages of their ventures; as such, attracting appropriate investors to support their entrepreneurial ventures is essential if their businesses are to grow and succeed. Entrepreneurs, however, typically face challenges in convincing investors of their ventures at this stage due to the "liability of newness" associated with their ideas, with often little in the way of a track record, obvious asset value, or profitability to show (Brush, Greene, \& Hart, 2001; Cassar, 2004). In this context, how entrepreneurs communicate about their ventures is crucial for convincing stakeholders to support the ventures and securing investment that can allow these entrepreneurs to further develop their ventures (Bird \& Schjoedt, 2009). Most prior research on entrepreneurial communication has focused on linguistic forms of communication, including how entrepreneurs use specific forms of speech such as rhetorical argumentation and narratives to impress a particular understanding on stakeholders (Aldrich \& Fiol, 1994; Navis \& Glynn, 2010; Van Werven, Bouwmeester, \& Cornelissen, 2015).

Here we focus on a specific form of entrepreneurial communication, the investment pitch, which has emerged as the industry standard in recent years whereby entrepreneurs present and describe their venture ideas to prospective investors over a period of 5 to 10 minutes (Brooks, Huang, Kearney, \& Murray, 2014; C. Clark, 2008). As Pollack, Rutherford, and Nagy (2012) stated, "the 
communication-focused behavior of pitching to potential equity stakeholders, such as angel investors and venture capitalists, is one of the most important behaviors that an entrepreneur will enact in the exploitation process" (p. 912). High levels of uncertainty characterize such pitches as investors have to judge the feasibility of a venture and its future capacity to generate revenue based on the limited information provided in the pitch. Although a good pitch is unlikely to overcome a baseless or flawed opportunity, having an excellent idea is not sufficient to ensure funding, and "without a good pitch, resources will not likely be forthcoming" (Pollack et al., 2012, p. 917). In sum, investment pitches offer an opportunity for entrepreneurs to personally communicate their ideas, and a successful "performance" is essential in gaining support and resources from investors (Cardon, Wincert, Singh, \& Drnovek, 2009; Chen, Yao, \& Kotha, 2009).

Like research on entrepreneurial communication more generally, previous research on entrepreneurial pitches has tended to primarily focus on the linguistic and rhetorical strategies that entrepreneurs use to persuade investors to fund their ideas (C. Clark, 2008; Pollack et al., 2012). Mason and Harrison (2003), for example, analyzed the reactions of 30 business angels to a video recording of an entrepreneur's real-life pitch presentation and found that the clarity, content, and structure of the presentation featured heavily in business angels' decisions on whether to invest. Pollack et al. (2012) highlighted the pitch as a narrative process through which entrepreneurs craft and tell a story that engages investors by justifying the existence of the venture and convincing them to offer their financial support. While there have been suggestions that embodied dimensions of pitching may be important, related research has been limited (Huang \& Pearce, 2015). Alongside narrative structures, Chen et al. (2009) examined the importance of entrepreneurs expressing passion while making pitch presentations, defining passion as the use of energetic body movements, rich body language, and animated facial expressions. More recently, Clarke et al. (2019) showed that while employing verbal strategies in pitching to investors, entrepreneurs also use hand gestures to emphasize important points and help convey product and venture ideas.

We aim to build on this research by attending to the embodied aspects of entrepreneurial communication observed during pitch presentations. In particular, we argue that entrepreneurial pitches provide one interesting and high-stake context from which to examine how gestures are used in organizational communication, and we thereby aim to contribute to previous literature in these areas, which has overlooked the entrepreneurial body as a key semiotic domain in pitch presentations.

\section{Protocol for Gesture Analysis in Naturalistic Settings}

In the following, a six-step protocol for gesture analysis is described drawing on an original data set of video recordings of investor pitches. As we outlined previously, we see investment pitches as a particularly appropriate setting to develop and apply our protocol given that research is increasingly showing that effective communication through both speech and gesture is integral to an entrepreneur's success (Clarke et al., 2019). However, the protocol we outline in the following can be applied far beyond this domain in a wide range of organizational communication contexts. This could include formal and informal organizational presentations and interactions (briefings, keynotes, meetings, or discussions) either with small or large groups of individuals. Figure 1 provides a visual overview of this protocol for gesture analysis in naturalistic settings.

Step I: Data collection. Gestures are fleeting and appear in subtle and sudden ways in naturalistic settings. Attempting to analyze gestures from memory or through note-taking would therefore be very difficult, and so video recording gestures for later analysis is the standard approach. This audiovisual capturing of gesture aligns with recent developments in organizational research where video is fast becoming a key resource for those studying communication and multimodality (C. Goodwin, 2000a; Gylfe et al., 2016; Heath, Hindmarsh, \& Luff, 2010; Hindmarsh \& Llewellyn, 2018). 


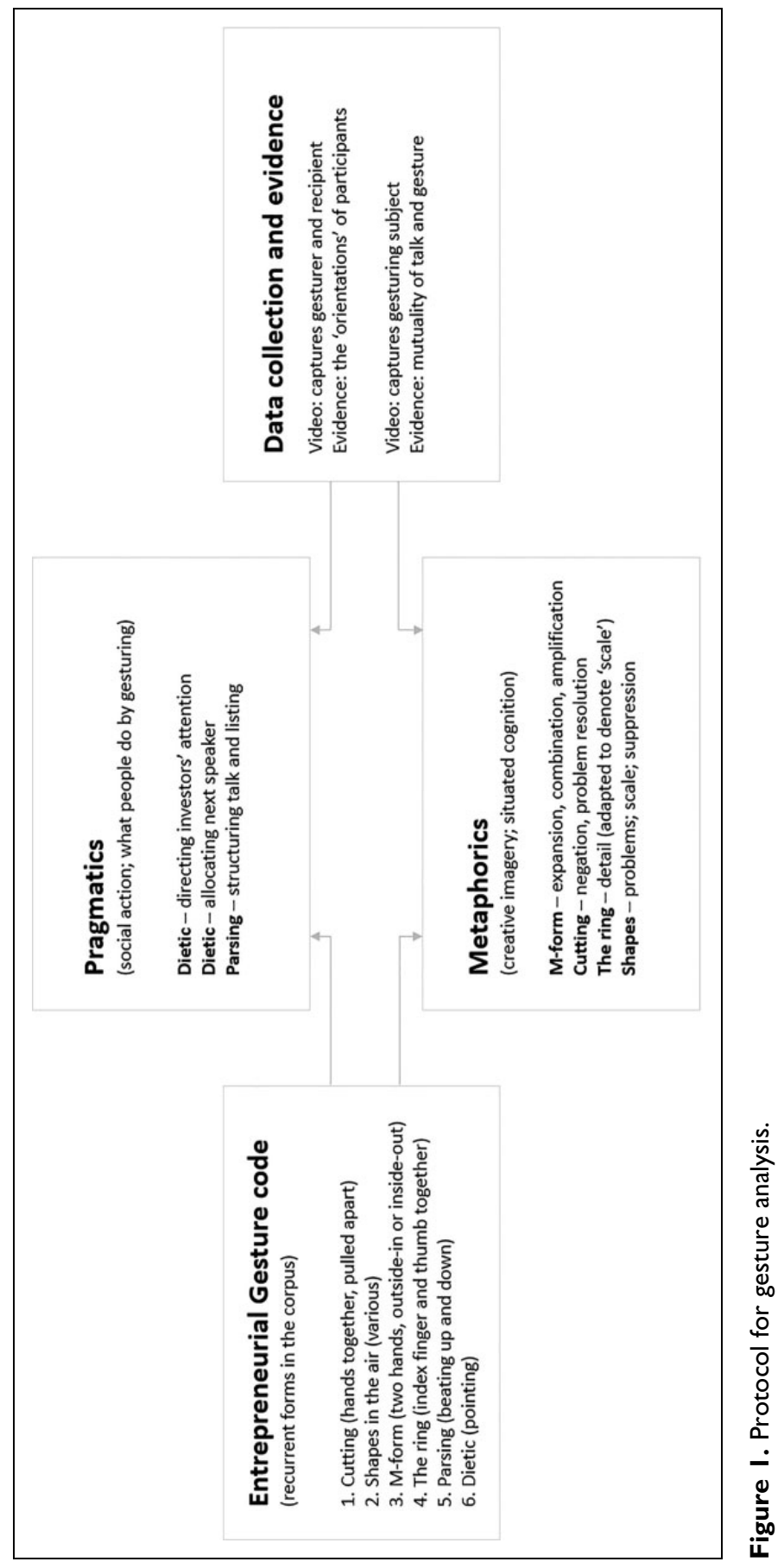


Video analysis allows us to examine "starkly visible 'extralinguistic' features," creating new possibilities for researchers by facilitating microlevel analysis through the repeated scrutiny and frameby-frame examination of the same motion/speech events (Kress, 2011, p. 253; Luff \& Heath, 2012).

For the present article, data were collected by one of the authors who attended Business Angel pitching events throughout the UK, collecting 54 video-recorded investor pitches. All speakers signed an ethics approval form, and all investors were given a chance to opt out, meaning that any questions they asked would be removed from the digital record. When introducing the project, our interest in gestures was not revealed to limit the likelihood of speakers reflexively or playfully gesturing during their presentations.

Videoing interaction is, to differing degrees, intrusive. A common question concerns whether participants alter their behaviors when videotaped. Entrepreneurial pitches are, however, routinely videotaped, and the presence of the video camera was not considered at all unusual. Rather than asking whether videotaping changes participants' behaviors, an alternative approach involves considering how people orient themselves to the camera by thinking in terms of analytics rather than ethics (Speer \& Hutchby, 2003). In our data, for example, one entrepreneur oriented to our camera through a dietic (pointing) gesture when explaining the difference between what it costs to make the presented product and its selling price. Gesturally, he implies that the video will "give the game away." A camera is thus used to enable the entrepreneurs to develop a sense that he is letting the investors in on "trade secrets."

The video camera was mounted on a tripod and placed at the back of the presentation room. Decisions on where to point the camera have drawbacks and should be theoretically informed. In cognitive linguistics, authors such as McNeill define "gesture space only with reference to the body of the party producing the gesture" (C. Goodwin, 2000a, p. 88). Microanalytic approaches (Schegloff, 1988) record both the body of the party making the gesture and interlocutors to recover how gestures are "oriented to" by others. For our data, this was a challenge because there were a large number of potential next speakers. At least two additional cameras would have been needed to capture key angles, which was deemed too obtrusive. A further approach would have involved allowing the camera to "rove," but this also presents drawbacks; it is difficult to anticipate where the next matter of interest will occur, resulting in the researcher being one step behind the action (Heath et al., 2010). Like all data then, ours present limitations; they were produced with a single fixed-position camera focused on each speaker and providing side views of audience members. Future researchers employing this protocol will also have to make similar tradeoffs between being excessively intrusive and capturing all activity; even in smaller group interactions, the position and distance of the camera must be carefully considered to ensure, for example, interlocutors are not unduly bothered by its proximity and location.

Step 2: Identify recurrent gestures. For expositional purposes, here we only consider how to recover the different embodied phases of gestures. At this point in the analysis, the focus is not on what the gestures mean, but rather the aim is to highlight the most common gestural forms in the data set. To understand the meaning or use of the gesture, the visual form must be combined with the speech, which we will consider in the next section (Step 3).

We performed an initial descriptive coding that first involved viewing and reviewing the video to identify recurrent gestures throughout the data. As typical in gesture studies, we focus predominantly on the stroke phase of a gesture, which is the gesture phase involving the most distinct exertion of effort, as opposed to the preparation phase leading up to the gesture or the retraction of the hand after the gesture (Kendon, 2004). Our corpus of pitches revealed a common repertoire of gesture shapes that ran alongside speech: (a) "cutting" (Kendon, 1994) or "slicing" (Streeck, 2008a), (b) "drawing shapes in the air" that represent semantic content (Kendon, 1997), (c) "M form" gestures from the center outward and from the outside inward, (d) the "ring" or "precision grip" (Napier, 1980), (e) parsing gestures (Streeck, 2008a), and (f) pointing. We found that this framework 
of key gesture forms accounted for much of the gesturing across the sample. These basic gestures are also likely to be present in many other forms of organizational communication given they have been extensively identified and detailed in a wide range of settings across the wider gesture literature (Streeck, 2008a).

Within the present sample, several of these gestures took a readily ideal-typical form that has been described in prior literature. Such gestures include the cut and precision grip (Kendon, 1994; Streeck, 2008a). These were identified relatively simply, as was their recurrence. A further class of pragmatic gestures directing the conduct of others was identified. These were also quite easy to identify because under the study settings, subjects typically use these gestures to perform one of two actions: selecting the next speaker or directing the visual attention of the audience members.

Other cases posed more challenges. In ongoing conduct, speakers cannot be relied on to reproduce well-known gestures starting and ending at rest. Rather, arms and hands often move constantly and sometimes idiosyncratically, with one gesture quickly morphing and blending into another. Many sections of data therefore require granular and repetitive empirical work. When viewed closely, for example, we found many seemingly random movements to be parsing out a pragmatic structure, namely, the hands would rise and fall while beating out syllables. In the following, we introduce the "shape" of only the most recurrent gestures identified from our data set.

(a) Cutting gestures. In these pitching environments, one gesture that reoccurred is the side-stroke or cut (Kendon, 1994), and an illustration is provided in extract 1 . In this case, the hands and arms are initially at rest, and then they take an "excursion" (Schegloff, 1984). At the prestroke hold, both hands are raised with fingers outstretched and palms facing one another. The stroke phase involves them being brought together, after which they are pulled apart to the left and right with a swooshing motion. Of course, there are subtle variations

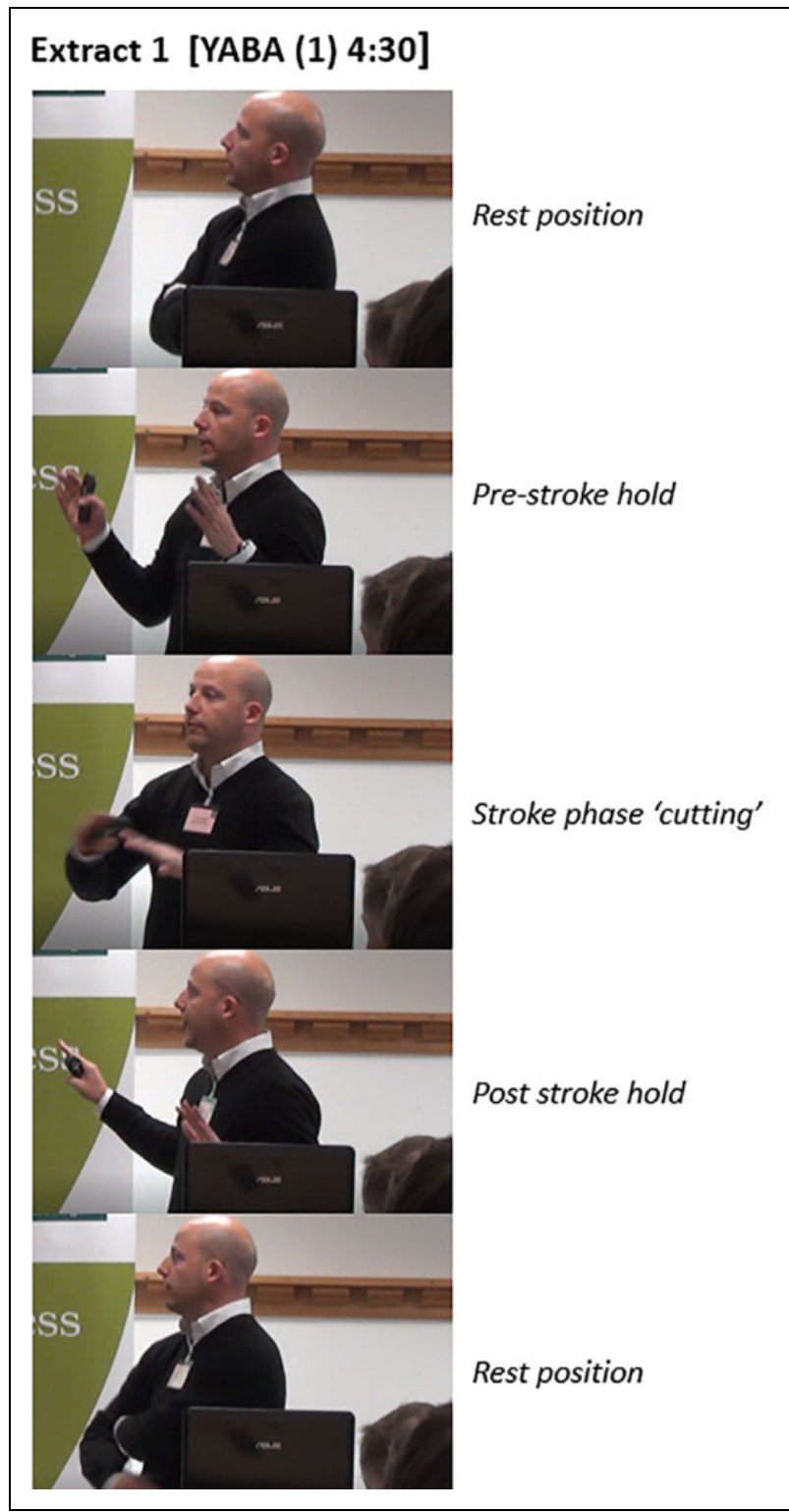


in practice. In some cases, the palms of the hand are held together, as if in prayer, before being moved apart in a cutting motion.

(b) Drawing shapes in the air. Entrepreneurs also routinely drew shapes in the air (Kendon, 1997). On some occasions, space would be fashioned as a quantitative tableau; gestures made close to the ground would depict something small, while the space above the speaker's head would be used to depict something large. Otherwise, a geographical tableau would be invoked. The space above the speaker denoted north, and the space close to the ground denoted south. Shapes "drawn" tended to be representational.

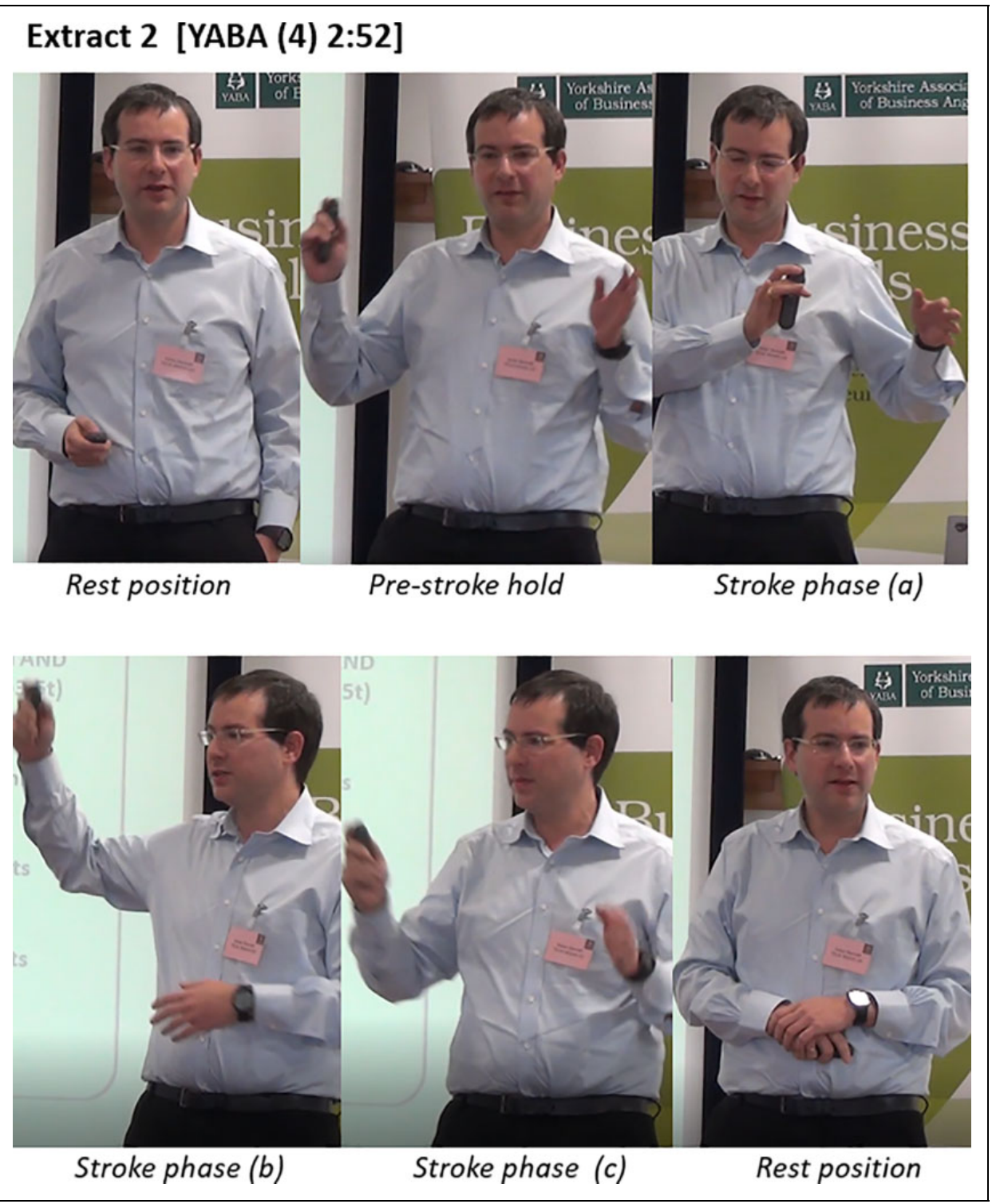


In the case illustrated in extract 2 , in the rest phase, the left hand is inert and the speaker is holding the clicker with his right hand. The gesture then begins. At the prestroke hold, both hands are raised apart with palms held open and facing one another. The gesture then involves three phases. While maintaining the formation, both hands move to the bottom left and are held there before the right hand moves to the top right with a rare lassoing motion before both move to the center (phase c). Analytically, the third phase (phase c) is part of the gesticulation and should not be confused with rest or retraction. With a rapid up-and-down motion, his hands mark the space in the center; they are doing something at this point. His hands then return to a rest position and are held across his middle.

(c) Outward and inward M-form gestures. Another common gesture was a distinctive M-shape drawn by the hands either from the center outward (extract 3 ) or the outside inward (extract 4).

For the prestroke phase illustrated in extract 3, the hands are drawn together from rest into the middle. The index fingers of both hands are touching. In the stroke phase, they are drawn apart outward and then upward along a curve. On occasion, the hands are moved all the way across and back to their starting position. In this case, they are held in the final position (the third image shown in extract 3 ) before immediately starting to perform a new parsing gesture.

In a second example (extract 4), the speaker starts with her hands positioned at the outside of the M-shape and then moves them inward. At the preparation phase, the hands are apart. The stroke phase brings the hands upward and inward until they meet. In this case, the speaker is gesticulating constantly. She moves into the prestroke hold from a prior iconic gesture to depict the shape of a container and from rest immediately into a parsing gesture.

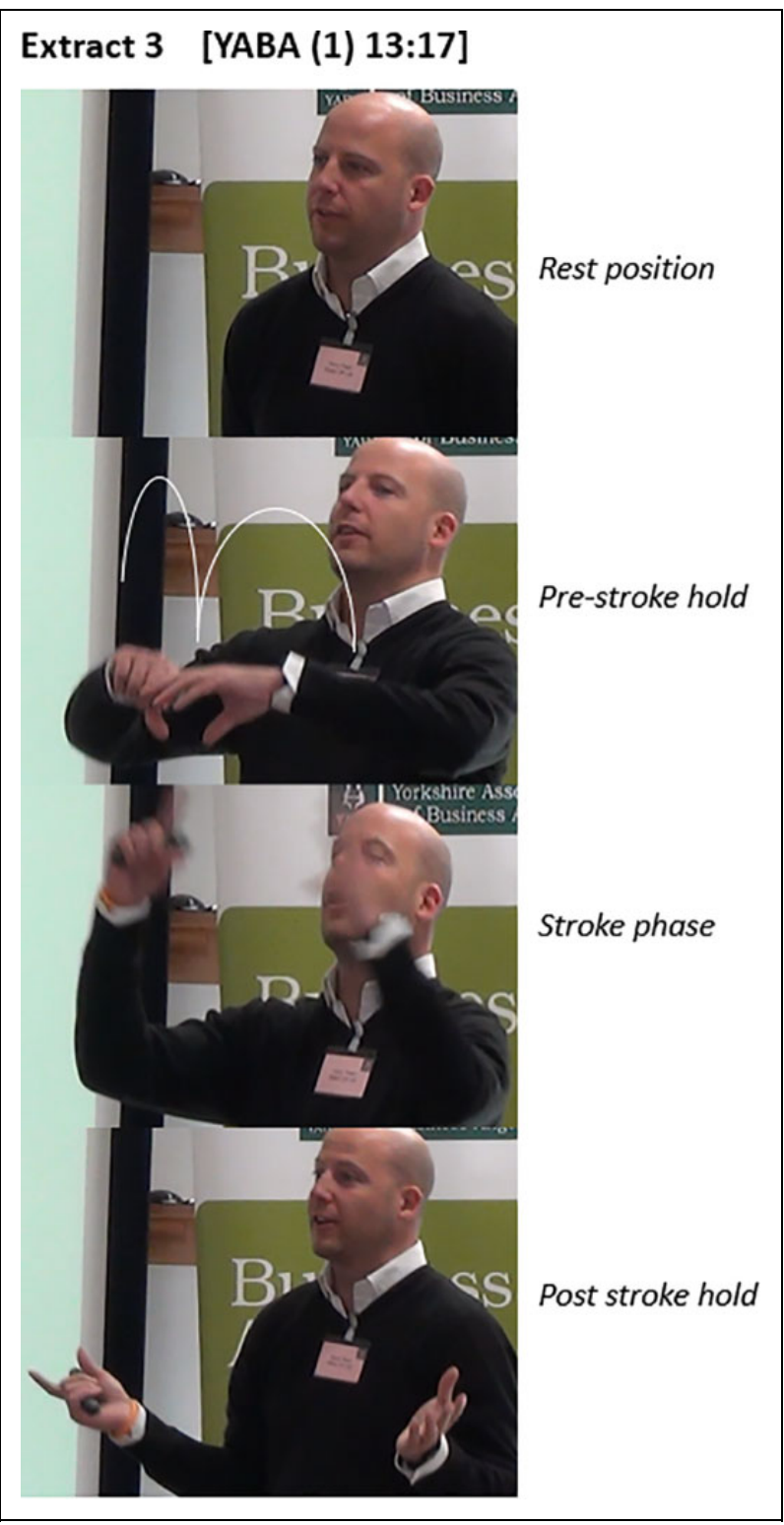




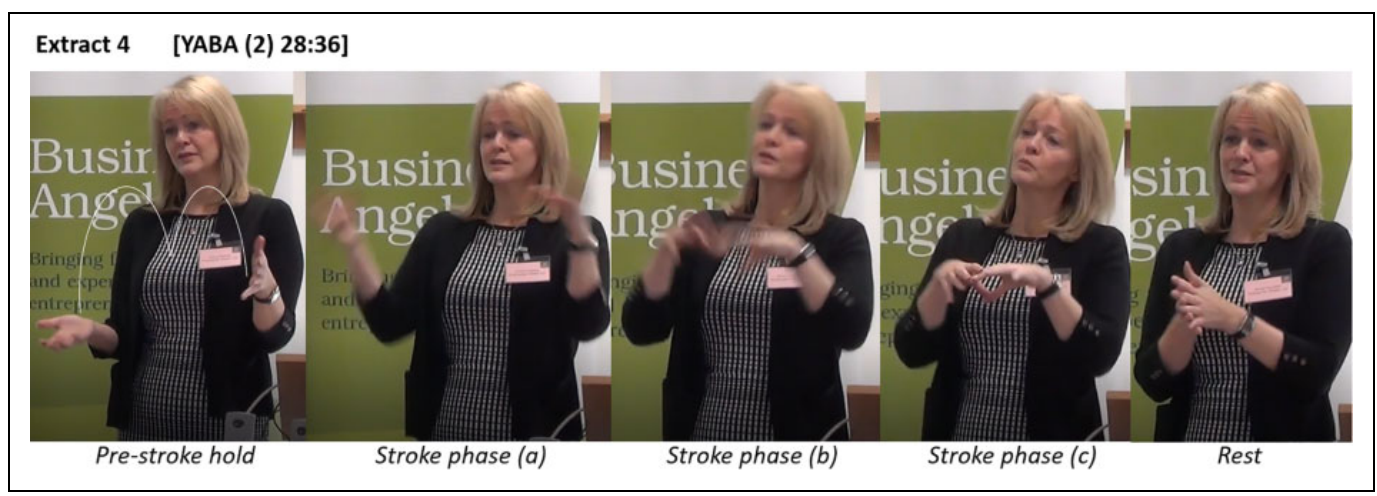

(d) The ring. The gestures mentioned thus far involve hands moving in expressive ways, but more subtle hand gestures are also significant. One such form reoccurs in our sample and is called the ring or precision grip (Napier, 1980). Here, the index or middle finger connects with the thumb, forming a circular shape to connote specificity or precision in everyday communication (Kendon, 2004).

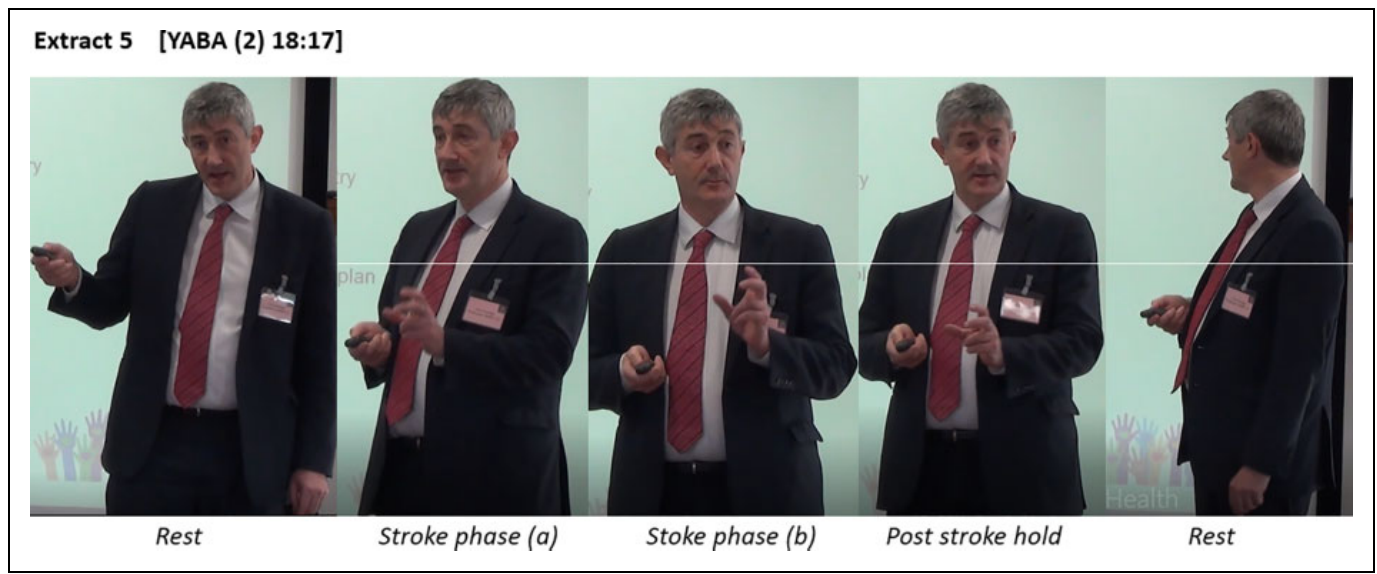

In the example illustrated in extract 5, the entrepreneur's left hand is initially at rest before being raised with the thumb, index finger, and middle finger, though without them touching. The gesture rises and falls. On three occasions, the grip moves up and down (for brevity, not all are shown in the images). This hand shape may be doing two things at once, denoting precision (Kendon, 2004) and parsing out semantic structure (Streeck, 2008a).

(e) Parsing or beating gestures. The most recurrent gestures observed in these materials are parsing gestures, where one hand rises and falls in isolation or in combination with the other. An example is provided in extract 6, where the speaker repetitively brings his hands together. In this case, from the images alone it might be assumed that the speaker is counting, as the right hand pulls back and is brought down on the little finger as if starting to count with a number sequence. As with all of the cases considered, this can only be determined when the visual form is combined with speech, as one modality elaborates the other. 


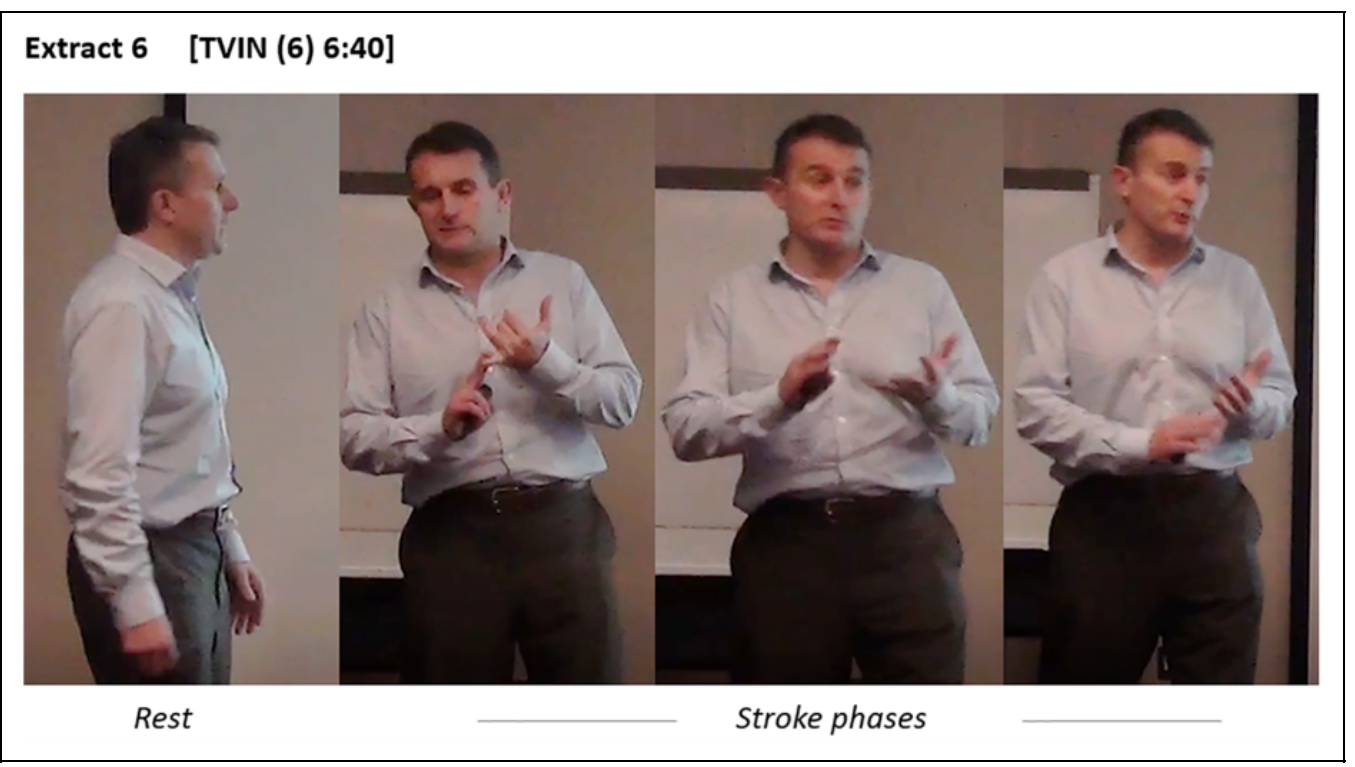

(f) Deictic gestures. Finally, while many of the gestures considered are metaphorics (McNeill, 1992) that communicate images of abstract concepts, pointing is more obviously involved in practical activity and in the business of directing the visual and embodied conduct of others (see C. Goodwin, 2000a). Very often, as is already apparent, entrepreneurs pointed at their PowerPoint slides and in this way found themselves in a close, expressive, and embodied relation with the material technology in the setting. Pointing directed the visual attention of audience members to the slides or specific details presented on particular slides. Entrepreneurs would point to direct the visual attention of the audience to objects within the room, and pointing was also a key resource used to manage speaker allocation and transitions.

Step 3: Link gestures and speech. We next incorporate speech into the analysis by examining how bodies move in relation to speech. Do gestures merely reflect speech, or do they also embellish it? Matters of timing are also considered; do gestures travel ahead, behind, or alongside speech? To the extent that speech and the body mutually elaborate one another, recipients may grasp the speaker's message not from hand movements alone but from the "configuration of activity" (C. Goodwin, 2000a) as a whole. It is in this step that we begin to see what the gestures are adding to the communicative account and the features that would ordinarily be neglected if gestures were not taken into account.

(a) Gestures that reflect speech. In a range of cases, the gestures considered reflected the lexical content of speech, acting to further emphasize or support the point or argument being made. Returning to extract 1 (as discussed previously), the speaker is framing the proposed business idea as a solution to a problem. This is a commonly recurrent feature of the observed pitches. Entrepreneurs describe business problems that they are eliminating; problems that they had initially experienced but can now be eradicated by using their novel product or service. It is in these communicative environments that we find side-strokes or cutting (Kendon, 1994) gestures. In extract 1, the speaker makes a cutting gesture (line 4) as he 
describes how his product removes a major logistical challenge associated with existing technologies ("you don't have to worry about that," lines 12-13).

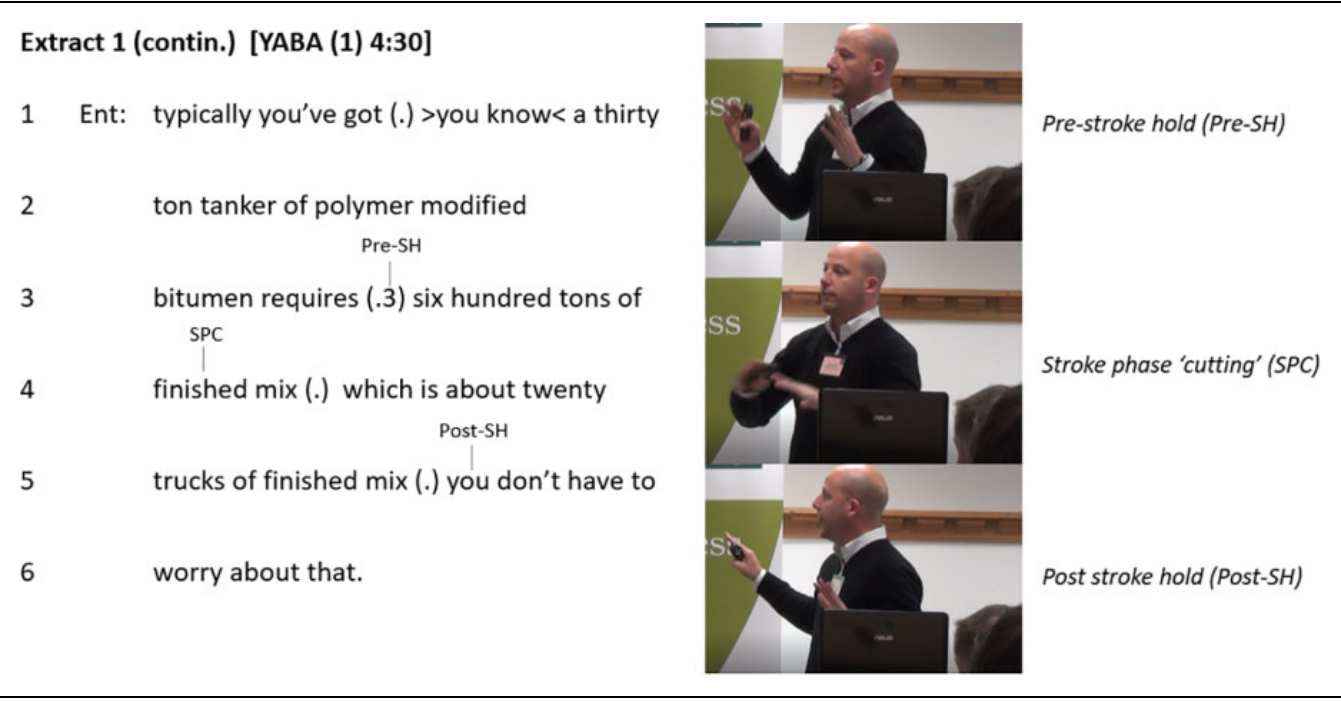

When we moved through our categories in this fashion incorporating speech, what emerged was a basic descriptive pattern of the way gestures aided the entrepreneurs in the communicative challenges they faced. To summarize, (a) the cutting (Kendon, 1994) or slicing (Streeck, 2008a) gesture routinely appeared as part of negation-talk where the entrepreneurs speak about overcoming problems. (b) Entrepreneurs drew shapes in the air particularly when spatially demarcating the markets for their products, while (c) M-form gestures denoted expansion or the establishment of new combinations. (d) The ring or precision grip (Napier, 1980) occurred where points of detail were presented or when unique selling points were described, while (e) parsing and (f) pointing gestures sectioned up speech. This framework is not exhaustive, and of course there are variations, but it serves as a useful starting point. We call this combined and refined typification of six gestural forms used alongside speech an entrepreneurial gesture code because the gestures are omnipresent across the pitches and are closely associated with the business of communicating entrepreneurial ventures, including matters such as expansion (into new markets), new resource combinations, negation (eliminating problems), demarcation (into different market segments), and specificity (unique selling points). When addressing problems related to entrepreneurial work, the body is enlisted in recurrent and recognizable ways. Future researchers drawing on this protocol can similarly develop a specific code for their organizational communication setting of interest based on the common gestural forms used alongside speech to achieve certain communicative goals in their particular research context.

(b) Gestures that embellish speech. Gestures often do more than simply reflect lexical content. They often either recast lexical content or add aspects not apparent from speech and would otherwise be overlooked if gesturing were not examined. An example is presented in extract 7 (see also extracts 10 and 11), which highlights the remarkably fine interplay between speech and the body. Here, in response to a question, the entrepreneur is explaining how his firm generates its margins. This hinges on the cost of inputs into the production process. The entrepreneur discusses alternative ways of repairing road surfaces, claiming that his 
product, made from recycled car tires and bitumen, is cheaper to make and use than the alternatives. From his speech alone, the entrepreneur is simply listing the cost (per ton) of the main three alternatives. However, when a gesture is drawn into the account, we see subtle ways in which the entrepreneur puts a slightly different spin on things, invoking images of value not present in the accompanying speech (C. Goodwin, 2000a). In this case, he combines two aspects of the entrepreneurial gesture code, namely, precision grip and sketching diagrams or shapes in the air (Kendon, 1997).

As the entrepreneur lists costs (line 1), he also starts his gestural work, raising his right arm. He draws a series of three lines in the air in the same direction away from his body. In each case, the line is mapped using the thumb and forefinger, which form a precision grip. The lines are drawn at three different heights, which correspond to a scale of value running from low (toward the floor) to high (upward).

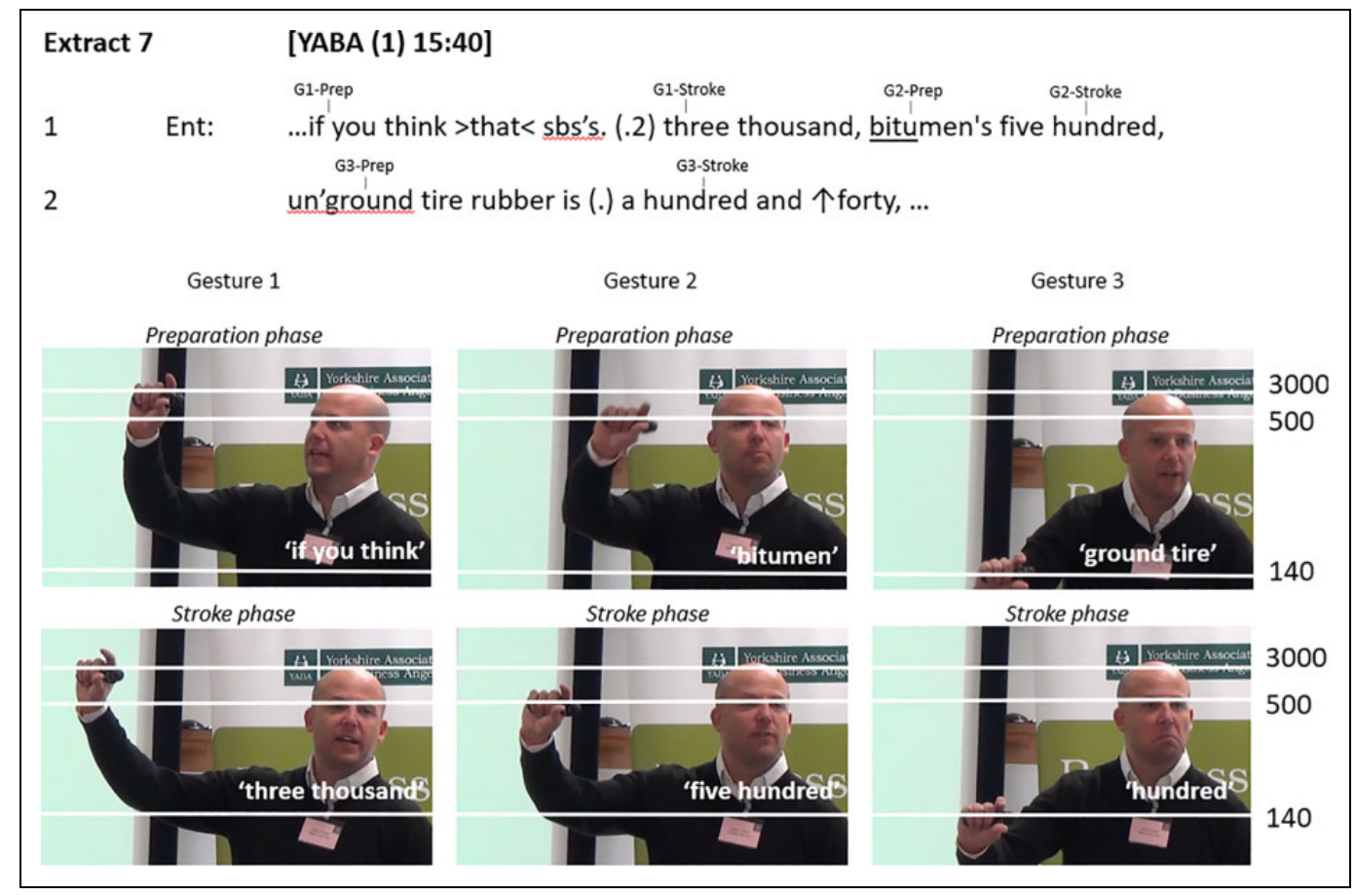

When the speaker embarks on each list item, he moves his hand into position and holds it there in preparation (Streeck, 2002). His hand only moves through the line as part of the stroke phase (Streeck, 2002) as he comes to the cost. The gesture marks not the pragmatic structure of his speech, namely, the beginning of each item on the list, but the item of real importance within each lexical unit - namely, the cost. Moreover, the gestural work does not literally depict quantities. The gap between 3,000 and 500 is considerably smaller at both the preparation and stroke phase than the gap between 500 and 140. The entrepreneur's cost advantage hinges on this second gap between bitumen and ground rubber. The numbers are organized in gestural space to persuasively inflate a sense of the firm's cost advantages. The gestures are not simple visual mirrors of lexical content "but a semiotic modality in their own right" offering additional and complementary information (C. Goodwin, 2000a, p. 1498). 
(c) Timing. Finally, and staying with the same speaker, we consider the matter of timing; whether speech and gesture coincide or indeed become temporally separated. Consider an example in this regard (extract 8). Here the entrepreneur is discussing the product that he is pitching, pellets, a sample of which are on display at the back of the room. Alerting the audience to this, he gestures toward the table where they are positioned before telling the audience where they are. His gestural work overtakes his speech. The pointing gesture is fully extended as he says "or" (line 1), which comes before he tells the investors where the pellets are displayed (lines 4-5).

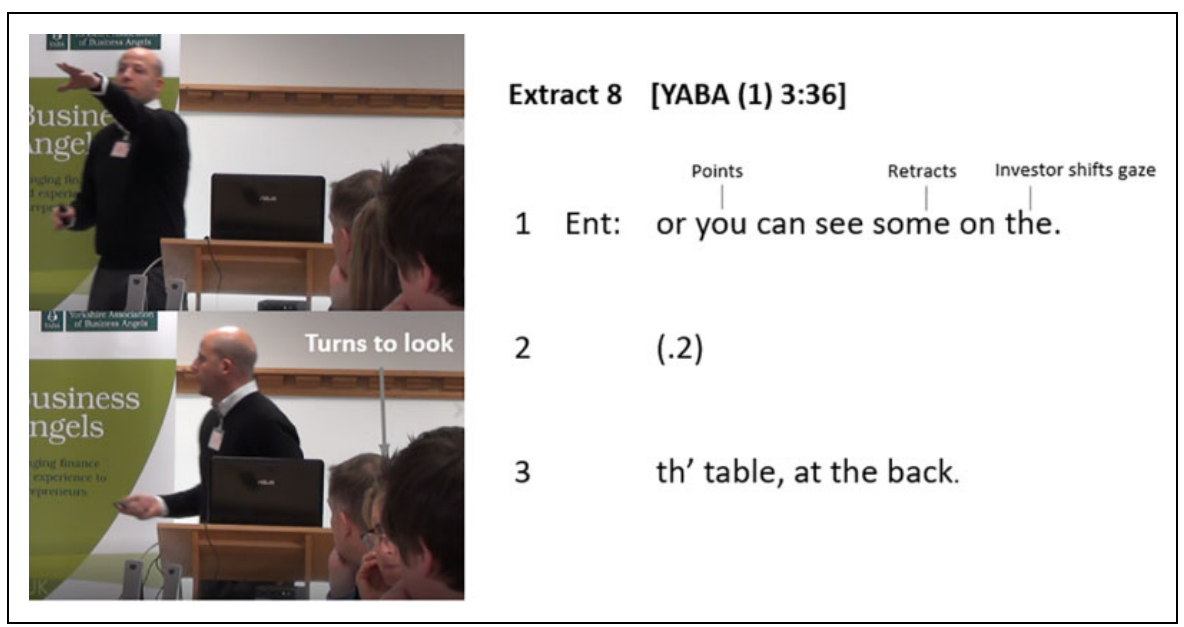

The fact that his gestural work occurs ahead of his speech is useful because when an audience member shifts her gaze to the back of the room (see middle image), we have strong evidence to claim that she is orienting her conduct to (Sacks et al., 1974) the speaker's gestural work rather than to his speech because she turns to look before the speaker states where the pellets are. We see here that gestures communicate (Kendon, 1994), with the audience member being guided to find the referent (in this case, the entrepreneur's product) from the gesture. The data capture her response and thus her sensemaking in how she has rendered the import of the speaker's embodied conduct.

Step 4: Link gesture and speech to the material context. We now incorporate materiality into our analysis (Hindmarsh \& Llewellyn, 2018). The entrepreneurs we recorded were often holding a material object in one hand (see extracts $1,2,3,5,6,7$, and 8), and as we have seen, their gestures often involved two hands. As such, speakers needed to spontaneously develop local improvisations that allowed them to incorporate the material object into the gesture. For example, to perform a cutting gesture, which involves two flat palms, the speaker in extract 1 found a way to press the clicker into his open palm with his thumb. In extract 2 , the speaker sketched shapes in the air to demarcate his market. He points to the floor with both hands to denote the market for small trucks, but he is holding the clicker in his right hand and thus must adapt. His little and third finger move off the clicker to point while his grip is maintained by his index and ring fingers. 


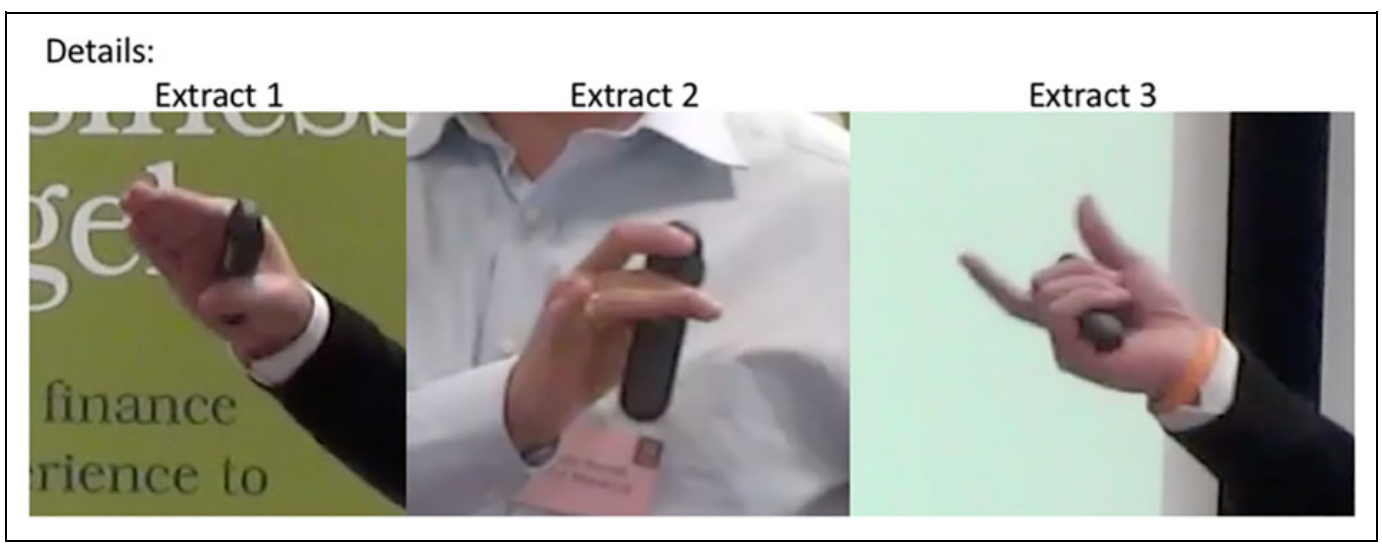

In extract 3, the speaker makes an expansive gesture, drawing an m-shape in the air. He improvises by sketching the curve with the thumb and index finger of his encumbered right hand.

The clicker does not act in isolation but in tandem with slides projected onto a screen behind the speaker. Entrepreneurs elaborated on their slides verbally and by gesturing toward the screen. We found that entrepreneurs often engaged the gesture code narrowly and infrequently when presenting to slides. The body became progressively less active. Unless entrepreneurs established localized improvisations, gestures became limited to parsing, pointing, and listing semantic content with the clicker used as a conductor or baton.

When speakers placed the clicker down before taking questions, a transformation was often evident. The inert right hand suddenly became active. In extract 9 (further), for the duration of the presentation, the speaker's left hand only performed parsing and pointing gestures. The gesture code is engaged in a limited manner. After 18 minutes, 41 seconds, the clicker is placed down, and the mode of bodily engagement has changed. Immediately, both hands expressively gestured together and toward the audience. When not active, the hands assume an entirely new at rest position, ready to be called into action. To understand patterns of engagement with a gesture code, it is necessary when analyzing gesture in any naturalistic setting to explore how materiality enables and constrains gesturing rather than making premature assumptions about an interlocutor's gestural expressivity.

Step 5: Analyze the interactional and pragmatic functions of gestures. Kendon (2017) suggested that gesture studies tend to be positioned between one of two central poles, namely, between an actionoriented concern with the pragmatic and interactional work performed by gestures and cognitive approaches that view gestures as providing insight into how people are thinking. In this step, we consider the pragmatic work performed by the gestures. Gestures supply people with resources for performing social actions (Kendon, 2017) and can contribute in a range of ways to multiparty interactions (Goodwin, 2000a; Schegloff, 1988). In the present data corpus, gestures were deployed to perform two recurrent sets of social actions: (a) speaker allocation, namely, passing on a question to a copresenter or selecting an audience questioner, and (b) guiding the attention of audience members to an object, person, or detail within the room. Examples are considered in the following.

Methodologically, those analyzing the pragmatic function of gestures can claim strong evidential basis (Sacks et al., 1974) that gestures do what they claim. An illustration is already presented in extract 8 . In this case, because the dietic gesture occurred ahead of speech and the video captured the embodied response of an audience member who turned and redirected her gaze before the speaker mentioned the whereabouts of the object, we were able to gain a strong evidential warrant (Sacks 
et al., 1974) for the claim that the gesture itself did something, namely, it guided the audience member's conduct and directed her attention within the scene. The analyst can ground his or her interpretations by taking into consideration the displayed orientations of participants who, confronted with a gesture, determine and display what they take the gesture to mean. In addition to recovering social actions performed by gestures, they can be analyzed pragmatically to recover rules and norms operative within organizational settings. In this sense, gestures are both interactional and social. As an example, take extract 9, where the entrepreneur gestures toward an audience member. From the visual channel alone, the gesture itself might be confused with a blocking gesture. The hand is held in front of the speaker with the palm raised and facing the recipient as if to request that they stop talking. Quite to the contrary, the gesture is pragmatically oriented to by all parties as selecting an audience member to speak.

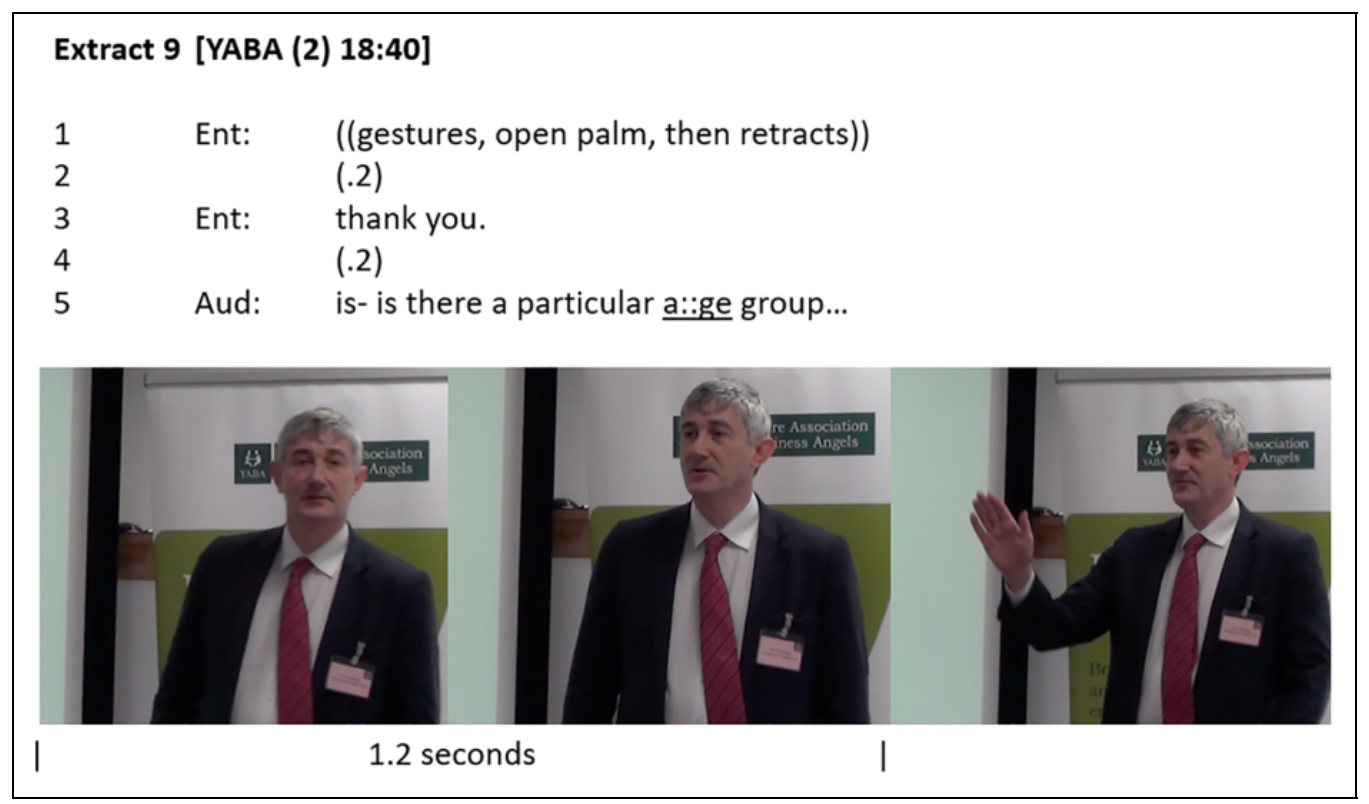

To grasp how the gesture is oriented to in this fashion, we must consider not just speech and materiality but also an appreciation of norms within the setting in which the gesture engages. In this case, the entrepreneur has just placed the clicker down, signaling the end of the presentation phase of the pitch. He pauses and looks up, accountably scanning the audience for a question. He orients to a new participation framework (Goffman, 1981). As he does so, a hand is raised in the audience just wide of the shot. The entrepreneur orients to this emblematic gesture (i.e., a raised hand) by gesturing toward the investor (captured by the image) with his palm raised and facing the recipient. Rather than preventing the individual from speaking, he is clearly identifying them as the next speaker with a dietic gesture. This hinges not on the handshape itself or on what the speaker is thinking but on where the gesture appears in this unfolding sequence. As his gesturing hand moves back to a resting position, the entrepreneur says, "thank you," verbally marking the successful accomplishment of the embodied work performed by their mutually elaborating gestures.

The subtle normative nature of this stretch of embodied conduct is apparent enough. The investor does not simply shout out a question. Rather, the investor waits for an appropriate time to make a 
contribution by making a gesture that signals a desire to speak. In and through this gestural work, the parties orient to and reproduce a simple social constraint that is relevant to the organization of conduct in this setting.

The two examples presented show how gestures direct the conduct of interlocutors and how they can thus be understood as intersubjective accomplishments rather than, for instance, products of mind or some underlying reasoning. For LeBaron and Streeck (2000), gestures “originate neither in the speaker's mind nor in the process of speaking ... rather gestures originate in the tactile contact that mindful human bodies have with the physical world" (p. 119). In the cases considered, clear evidential grounding for analytic claims is noted, arising from the fact that the gesture relevance was oriented to by participants themselves.

To some extent, whether studies pursue interactional work performed by gestures or examine the insight that gestures provide into how people are thinking (Kendon, 2017) will reflect prior theoretical commitments. However, we argue that they should also be driven by pragmatic considerations on the nature of the setting considered-with such theoretical commitments emerging from observations and initial gestural depictions. When a surgeon gestures to request a scalpel, the central concern in this setting is pragmatic, namely, whether the action implication of the gesture is recognized accurately and swiftly. What the surgeon is thinking is comparatively less interesting. In other settings, the reverse is true. In analyzing the business keynote speeches of Steve Jobs, Wenzel and Koch (2018) described the central role of expressive gestures. However, during the examined keynote speeches, gestures did not play a strong pragmatic role, and audience members could only exhibit collective affiliation with the message by applauding or cheering. For keynote speeches, the key question concerns how speakers communicate their thoughts. Likewise, with investor pitches, audience members are for the most part listening rather than directly responding to what is said. As such, in our data, the pragmatic functions of gestures are largely secondary to what the gestures represent or convey to an audience. Investors wanted to hear business ideas and concepts and be engaged with the entrepreneur's vision, and it is to this point that we now turn. Therefore, in future research using this protocol, the interactivity of interlocutors in the specific organizational context will play a role in the level of importance attached to the pragmatic function of gestures in the analysis.

Step 6: Gestures and metaphors. Finally, we incorporate a specific concern with metaphorical gestures and the images that entrepreneurs create through their speech and their body to communicate ideas. This sixth step is based on strong evidence from the multidisciplinary field of gesture studies (Cienki, 1998), which shows that a large proportion of gestures across communicative contexts are metaphorical in nature, depicting abstract ideas through concrete gestural embodiment and symbolization. In the specific context of entrepreneurship, metaphors can encode and articulate novel ideas that entrepreneurs have in terms of familiar domains of understanding that when well chosen, may deeply resonate with, reassure, or stimulate recipients (Cornelissen \& Clarke, 2010).

To illustrate the importance of metaphors in gesture using our data set, we start with extract 10 . Clearly, this extract is laden with metaphorical expressions and imagery. A source domain for each metaphorical word or expression was developed to characterize the underlying metaphor (Pragglejaz, 2007). Words used metaphorically are underlined, and the associated source domain codes follow in brackets and capital letters. Many of these correspond with source domains identified elsewhere within cognitive linguistics (Grady, 1997, 2005; Lakoff, 1993; Lakoff \& Johnson, 1980, 1999). 


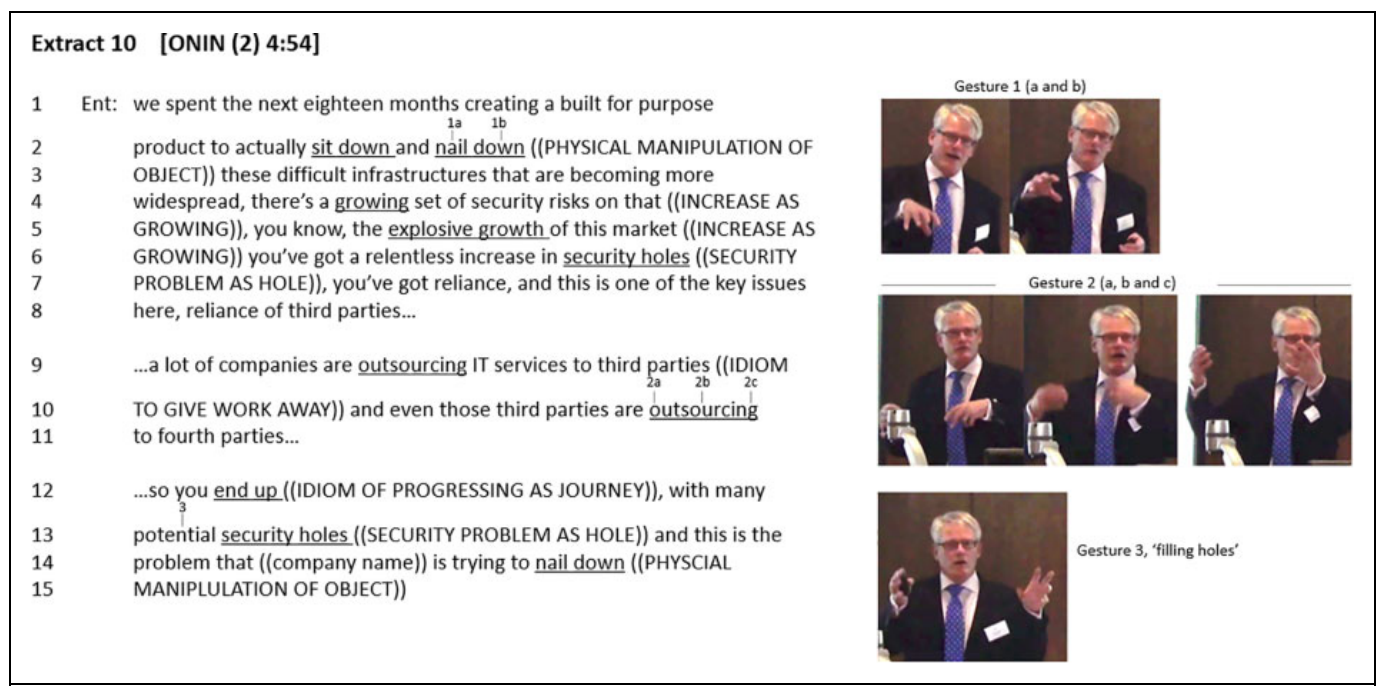

In this example, considering the interplay between metaphorical speech and gesture reveals several interesting general patterns in our material, including gestures that: (a) embellish verbal metaphors, (b) add metaphorical elements to nonmetaphorical speech, and (c) cue upcoming metaphors used in speech.

As the extract begins, the entrepreneur has both hands apart and facing each other, palms held flat. In the stroke phase, the right hand moves into a claw-like formation and rises up and down numerous times in succession. Rather than parsing semantic content, this is a metaphoric gesture; he is pushing something down, which then rises up. The gesture represents the company trying to "nail down" (line 2) a solution to security problems in the cyberspace market. His gestural work is engaging and embellishing the metaphoric content of his speech. The gesture is not literal; the speaker does not depict the act of hammering down a nail but rather emphasizes a downward motion representing the battle to suppress problems that would otherwise spread.

Gestures can also contribute entirely new metaphorical elements (see also Cornelissen, Clarke, \& Cienki, 2012). Consider the second gesture (gesture 2) in extract 10 (lines 9-11). In the preparation phase, the entrepreneur moves his hands together and turns them so that the backs of his hands are now facing the audience. In the stroke phase, he moves his hands outward in an M-shape, and then he turns them so that his palms face the audience as if he has thrown or flicked something outward. This gesture elaborates on the term outsourcing invoked through his speech. His speech addresses how companies often outsource IT services to "third parties" who might also pass them onto "fourth parties." Although outsourcing is a highly conventionalized expression, we see that the speaker physically activates this expression through gesture by moving his hands to enact the movement of throwing or giving something away. For cognitive linguistics, this gesture stands as evidence of the speaker's situated cognition; he is thinking in an embodied fashion, illustrating metaphorically that companies are "handing" work to others.

Metaphoric gestures can also occur ahead of speech, cueing audiences about forthcoming content. This idea is illustrated when the entrepreneur states that outsourcing results in a number of "security holes." In this case, he produces a metaphoric gesture before articulating the verbal metaphor. While shaping his right hand like a claw facing toward the audience, he moves in a manner that suggests placing an object into a space or filling holes.

A second extract (extract 11) is also dense with embedded metaphors. As the extract begins, the entrepreneur verbally likens digital information about his clients to a sound that may be amplified. 
There is an accompanying gesture that embellishes this metaphor. In the preparation phase, the entrepreneur's hands are touching with both palms facing one another at the center of his body. In the stroke phase, he produces an expansive M-form gesture where both palms move upward and outward and then down in an arching motion. The gesture works together with the verbal content, clarifying the metaphor. The gesture represents not only a simple increase (in volume) but also an expansion and growth outward from a central point.

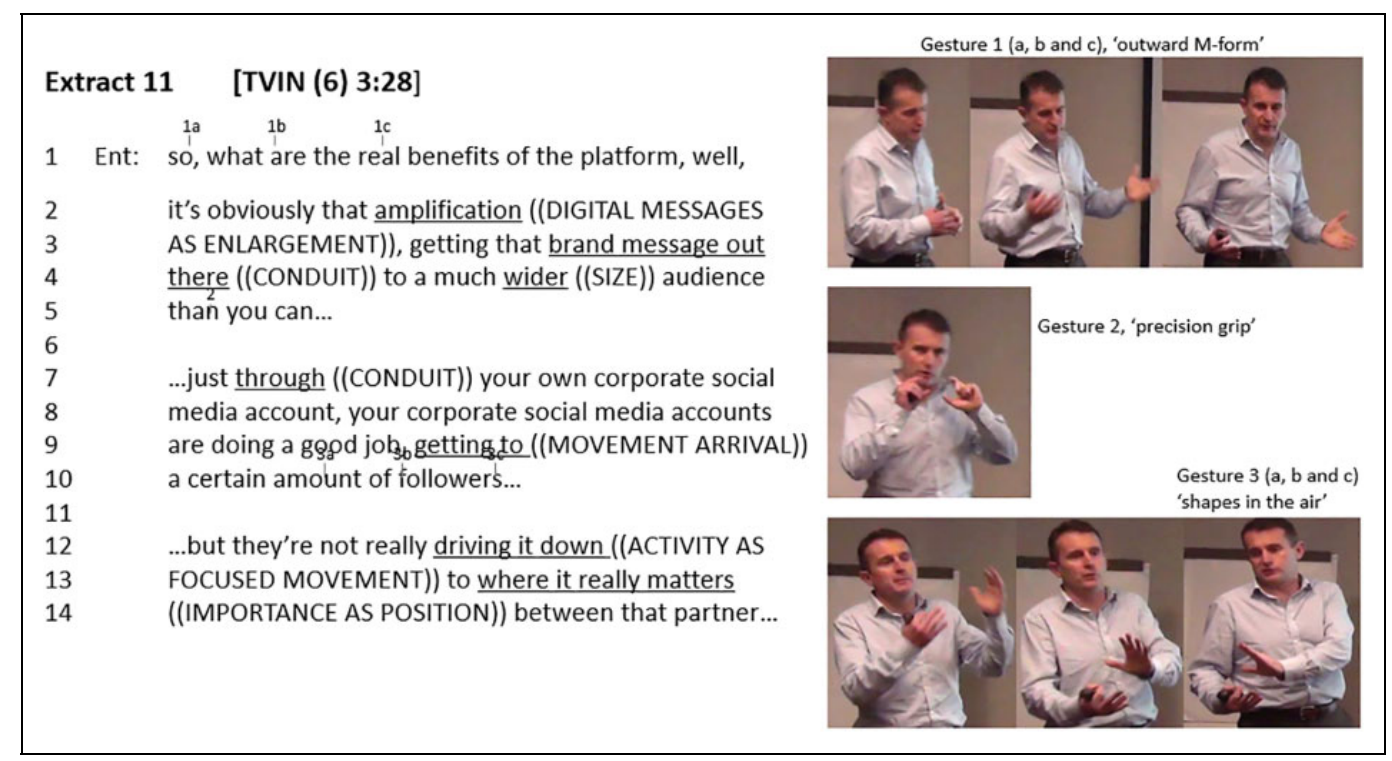

The outward M-form gesture denoting amplification is quickly followed by a second gesture, an adaption of the precision grip where the index fingers and thumbs of both hands are arranged as if holding very small objects in order to depict the small number of followers that clients can generate through their own social media accounts. A creative invocation of scale-based gestures is apparent. In extracts 2 and 7, the entrepreneurs invoked a scale of low/small (toward the floor) to high/large (toward the ceiling). In extract 11, the entrepreneur uses the M-form (denoting large) and an adaptation of the precision grip (denoting small).

In the final gesture in extract 11 (lines 12-14), the entrepreneur moves his hands in three successive movements as if he is pushing (or driving) an object downward into an imagined space. He is describing how his social media company can enhance his clients' online presence by digitally driving or forcing information into social media sites. He draws on these familiar embodied movement metaphors to convey meaning to investors in a way that naturalizes how the product works and the overall feasibility of the venture.

From these data, we see that metaphors can encode and articulate business ideas in terms that are already largely familiar to listeners or recipients (Cornelissen \& Clarke, 2010). The metaphors used in speech combine powerfully with gestures and work to compress the complex development of novel ventures into familiar categories or scenes and may be crucial to how entrepreneurs transfer their ideas to the public domain and allow others (employees, investors, customers, etc.) to better understand the venture, thereby achieving "shared cognition" (Cardon, Zietsma, Saparito, Matherne, \& Davis, 2005; Cornelissen, 2005; Hill \& Levenhagen, 1995).

Metaphoric gestures can help entrepreneurs but also other organizational actors such as CEOs, strategists, team leaders, and so on (Gylfe et al., 2016) to communicate effectively with others 
through enabling listeners to understand new ideas or unfamiliar situations through familiar domains of embodied knowledge (e.g., Alibali, Heath, \& Myers, 2001; Gibbs, 2006; Grady, 1997; Lakoff \& Johnson, 1999). Specifically, by simulating bodily experiences, metaphoric gestures play a role in helping us process metaphoric and abstract expressions (e.g., Boulenger, Shtyrov, \& Pulvermüller, 2009; Gibbs, 2006) and can convey meanings more directly or more clearly than the accompanying speech (Cienki, 1998; McNeill, 1992). As Gibbs (2008) noted, metaphoric gestures combined with speech do not just communicate redundant information, but they "express something different" (p. 296). Listeners can use information from gestures to inform their constructions of meaning and help activate embodied intentions and plans for action (Gallese \& Lakoff, 2005; Iverson \& Thelen, 1999).

\section{Discussion}

In the article, we have argued that gestures are a significant aspect of human communication (Kendon, 2004) that have been largely overlooked in prior organizational research aside perhaps from recent video-based studies that consider embodiment and multimodality more generally (see Hindmarsh \& Pilnick, 2007; LeBaron et al., 2016; Llewellyn, 2014). The present article demarcates gestures as a specific subset of embodied conduct (Kendon, 1994) and as a distinctive modality with its own forms and discourse functions.

We developed a protocol for gesture analysis in naturalistic settings and have illustrated this protocol through the analysis of an original corpus of video-recorded investment pitches. We considered recurrent gestures used to elaborate on and embellish key entrepreneurial messages through the "entrepreneurial gesture code," including how aspects of this code are enlisted to perform social actions in line with a microanalytic approach (C. Goodwin, 2000a; Heath, 1986; Streeck, 2008b) and to enliven, introduce, and cue abstract ideas and metaphors drawing on resources from cognitive linguistics. We found investor pitches to provide a rich context where the gestural expressions of entrepreneurs are likely to play a role in the impressions that investors form. When entrepreneurs delineate their markets, explain the basis of their margins, and describe their products, these explanations cannot be reduced to speech or text. We found gestures are rarely passive reflections of verbal content and that verbal content rarely expresses the totality of meaning conveyed by a speaker. Examining gesture in these communicative episodes offers us a more holistic understanding of the verbal and embodied messages and their interplay, which would be missed if the focus were solely on rhetorical or narrative strategies. Not attending to the gesture in organizational interactions will allow much of the embodied nature of communication to go unnoticed.

While there are many gesture forms, we have demonstrated that in particular settings, speakers may draw on a relatively narrow repertoire. This recurrent use of a small number of gestures forms is apparent in other gesture research also; for example, in analyzing the speeches of democratic presidential candidates, Streeck (2008a) identified a gesture code consisting of four main forms: the slice, pointing, the power grip, and the ring. Gestures are perhaps less idiosyncratic than might be imagined. Moreover, it is therefore possible to gain a degree of analytic traction from large data sets relatively quickly as the analyst can identify recurrent gestures and how they engage with other modalities to perform actions and convey particular images and metaphors. The protocol we have developed here should enable such work in other organizational contexts, describing key analytic challenges and illustrating how they can be addressed: (1) how to video record gestures in an inductively rich but theoretically informed fashion; (2) how gesture phases (rest, prestroke hold, stroke phase, poststroke hold or retraction, rest) should be identified and how to deal with complicating issues; (3) how the relation between gestures and speech can be accessed, identifying gestures that reflect, embellish, or add content and recovering the temporal relation between gestures and speech; (4) how to empirically recover the ways in which materiality enables and constrains 
gestures; (5) how gestures perform social actions, for example, how dietic gestures direct the conduct of interlocutors and how gestures embody norms within social settings; and (6) how the role of gestures function in the construction and extension of metaphoric content and in the engaging expression of ideas. Our protocol supplies resources for analyzing the three main categories of gestures described by Kendon (2015), namely, pragmatic, deictic, and representational.

While presented in a fairly pragmatic fashion, the protocol we have developed crosses various theoretical lines that divide approaches in terms of their operation and underlying assumptions. As Kendon (2017) noted, methodological resources for gesture studies have different histories and theoretical underpinnings that result in differences in foci and procedures. The microanalytic approach (Streeck, 2008b), which draws resources from conversation analysis (C. Goodwin, 1986, 2000a; Heath, 1986), analyzes the organization of social actions rather than the articulation of ideas. Streeck (2008a) is clear that the question of how "impressions are formed and how they affect people's... decisions are questions that cannot be answered by microanalysis" (p. 182). Microanalysis reveals the detailed order and organization of gestures' relations to speech, social norms, participation frameworks, and material contexts. For some researchers and in some settings, this will not be enough. For example, in the context of investment pitches, if we assume that investors make decisions at least partially based on pitches, then we need an analytic account of "what exactly it is that [investors] react to when they form impressions of [entrepreneurs] and judgements of the type of persons that they are" (Streeck, 2008a, p. 182).

While the microanalytic approach refuses to go beyond the data and grounds analysis only in the displayed orientation of participants, cognitive linguistics is guided by a priori theoretical insights, which suggest a particular relationship between speech, embodiment, and the thinking subject. Comparatively, it claims more empirical freedom to infer from speech and embodiment what people are thinking. From this theoretical perspective, metaphors have special importance, depicting scenes essential to human experience; this provides their use with "human scale" and a "direct and experiential basis" (Gibbs, 2006, p. 117), and from this basis they can be easily understood (Grady, 1997, 2005; Lakoff \& Johnson, 1999). Metaphors can reduce abstract or new ideas into existing embodied understandings that are concrete and more easily understood. The creation of such human-scale metaphorical scenes (i.e., ideas scaled to a level that can easily be understood in everyday imagery) and the employment of gestures in their articulation can support the individual's communicative goals in both the context of entrepreneurial pitches and other organizational communicative activities.

Although these approaches are built on different theoretical models and images of communication and interaction, there are intriguing overlaps between them. Most obviously, as with gesture studies as a whole, both share an interest in detailed microanalytic procedures of the type that allow for a finer-grained analysis of entrepreneurial communication than is available from prior work on investor pitches (e.g., Chen et al., 2009). Both use video recordings and analyze gestures in granular detail as they unfold through recognized phases. Both prefer to analyze speech and embodied activity in naturalistic settings and produce "situated" accounts. Both are nonindividualistic approaches - they view cognition and action as concertedly produced. In cognitive linguistics, shared ideas are at the heart of "understanding," which is likened to jointly establishing or building a physical base and often involves adducing metaphors to ground an understanding of abstract concepts such as new ideas or new ventures (Cornelissen \& Clarke, 2010). In conversation analysis, understanding is the product not of shared mental images but of common interactional procedures for displaying, checking, and repairing sense. Despite their different intellectual histories, both approaches have found their subject matter to be best understood through the detailed analysis of language use and embodied activity in naturalistic settings.

There is therefore some scope for developing synergies and dialogue between these two nonexperimental approaches to analyzing gestures and situated activity. In any setting, the 
establishment of "common ground" (A. Clark, 1996) between interlocutors relies on a suite of interactional practices described by conversation analysis, through which actors display and monitor "sense" turn by turn and "repair" troubles as they arise through actions performed through speech and other embodied behavior (Schegloff, 1995). However, establishing common ground between organizational actors can sometimes depend on more than this. For example, in the context described here, the uncertainty and ambiguity of the venture means the entrepreneur must also construct meaning for investors, compressing the complex and uncertain process of commercializing a venture into concrete and familiar scenes (Hill \& Levenhagen, 1995; Lounsbury \& Glynn, 2001). Here gestural metaphors may be mobilized alongside pragmatic gestures to achieve communication goals and arrive at mutual understanding. Thus, to understand how investors and entrepreneurs find themselves "on the same page," it is also necessary to engage a wider sense of semiotics. It is likely that such an enlarged sense of semiotics will also be useful for other organizational communicative episodes, and as such, there are grounds for bridge-building between these quite different approaches that may ultimately lead to novel hybrid research studies.

\section{Conclusion}

In this article, we have developed and applied a protocol for gesture research in natural settings, using the context of entrepreneur investment pitches as illustrative of one type of organizational communicating setting. In presenting a fine-grained analysis of gesture in an entrepreneurial context, we have illustrated the importance of attending to "modes" beyond the "verbal," indirectly challenging "language-only" versions of communication (McNeill, 2012).

In relation to research in the context of entrepreneurship, our analysis strongly suggests that studies of entrepreneurial pitching and communication should not restrict themselves to speech alone (Van Werven et al., 2015) but that future research should take account of its multimodal character and embrace a more embodied perspective. In this way, we add to recent calls for an embodied, situated, and interactive account of the entrepreneurial process (Mitchell, Mitchell, \& Randolph-Seng, 2014). Instead of seeing entrepreneurs as individual cognitive agents with thoughts largely stemming from their dispositions and mental states, an embodied perspective frames entrepreneurship as a dynamic process co-constituted by the actions that entrepreneurs initiate as part of the entrepreneurial process (Gylfe et al., 2016; Mitchell et al., 2014). In this sense, cognition and communication pair up with thoughts being interactively created and shared as entrepreneurs engage with others such as investors in context (Clarke \& Cornelissen, 2014). Specific modalities of communication, such as gestures, are able to prime and simulate action in others, impacting exchanges between entrepreneurs and investors.

As we have alluded to throughout, future research could use the protocol we present here to examine how gestures play out in a range of interactional contexts as the scope for examining gestures in organizations is much broader than solely entrepreneurship settings. Gestures are vital to a range of strategic communications and organizational presentation settings, including, for example, keynote speeches, CEO strategy presentations, annual general meetings, and press conferences (Biehl-Missal, 2011; Gylfe et al., 2016; Whittington, Yakis-Douglas, \& Ahn, 2016). Like pitches, such contexts represent high-stake scenarios for organizations in which actors must use all available bodily means to communicate effectively to large audiences to "raise awareness of, disseminate, rationalize, and mobilize support" (Wenzel \& Koch, 2018, p. 643). Future studies could also use the procedure described here to examine gestures in more informal day-to-day organizational interactions involving dyadic and small-group interactions, as the basis for effective communication to large audiences may be markedly different from communicating effectually with individuals. There is therefore much utility in detailed research conducted on speech and gestures used in more intimate organizational communications, both within organizations and with a variety 
of external stakeholders (e.g., customers, employees, and suppliers; Balogun \& Best, 2015; LeBaron, Jarzabkowski, Pratt, \& Fetzer, 2017). In sum, future research can draw on our protocol to develop a systematic and concerted focus on gestures that draws attention to the empirical and theoretical significance of gestures for organizational communication, discourse, and collaboration.

\section{Declaration of Conflicting Interests}

The author(s) declared no potential conflicts of interest with respect to the research, authorship, and/or publication of this article.

\section{Funding}

The author(s) disclosed receipt of the following financial support for the research, authorship, and/or publication of this article: This research was funded by the Economic and Social Research Council (grant number ES/K00185X/).

\section{References}

Aldrich, H., \& Fiol, C. (1994). Fools rush in? The institutional context of industry creation. Academy of Management Review, 19(4), 546-671.

Alibali, M. W., Heath, D. C., \& Myers, H. J. (2001). Effects of visibility between speaker and listener on gesture production: Some gestures are meant to be seen. Journal of Memory and Language, 44(2), 169-188.

Balogun, J., \& Best, K. (2015). Selling the object of strategy: How frontline workers realise strategy through their daily work. Organization Studies, 36(10), 1285-1313.

Bates, E., Benigni, L., Bretherton, I., Camaioni, L., \& Volterra, V. (1979). The emergence of symbols: Cognition and communication in infancy. New York, NY: Academic Press.

Bell, E. (2012). Ways of seeing organisational death: A critical semiotic analysis of memorialisation. Visual Studies, 27, 4-17.

Bell, E., Warren, S., \& Schroeder, J. E. (2014). The Routledge companion to visual organization. London: Routledge.

Berger, K. W., \& Popelka, G. R. (1971). Extra-facial gestures in relation to speechreading. Journal of Communication Disorders, 3(4), 302-308.

Bird, B., \& Schjoedt, L. (2009). Entrepreneurial behavior: Its nature, scope, recent research and agenda for future research. In A. L. Carsrud \& M. Brannback (Eds.), Understanding the entrepreneurial mind (pp. 327-358). New York, NY: Springer.

Biehl-Missal, B. (2011). Business is show business: Management presentations as performance. Journal of Management Studies, 48(3), 619-645.

Bouissac, P. (2008). Ecology of semiotic space: Competition, exploitation and the evolution of arbitrary signs. The American Journal of Semiotics, 10(3/4), 103-147.

Boulenger, V., Shtyrov, Y., \& Pulvermüller, F. (2009). When do you grasp an idea? MEG evidence for instantaneous idiom understanding. Neuroimage, 59(4), 3502-3513.

Bressem, J., \& Ladewig, S. H. (2011). Rethinking gesture phases: Articulatory features of gestural movement? Semiotica, 184, 53-91.

Brooks, A. W., Huang, L., Kearney, S. W., \& Murray, F. E. (2014). Investors prefer entrepreneurial ventures pitched by attractive men. Proceedings of the National Academy of Sciences, 111, 4427-4431.

Brush, C. G., Greene, P. G., \& Hart, M. M. (2001). From initial idea to unique advantage: The entrepreneurial challenge of constructing a resource base. The Academy of Management Executive, 15(1), 64-78.

Cardon, M. S., Wincert, J., Singh, J., \& Drnovek, M. (2009). The nature and experience of entrepreneurial passion. Academy of Management Review, 34(3), 511-532.

Cardon, M. S., Zietsma, C., Saparito, P., Matherne, B. P., \& Davis, C. (2005). A tale of passion: New insights into entrepreneurship from a parenthood metaphor. Journal of Business Venturing, 20(1), 23-45. 
Casasanto, D., \& Bottini, R. (2014). Spatial language and abstract concepts. WIREs Cognitive Science, 52(2), 139-149.

Cassar, G. (2004). The financing of business start-ups. Journal of Business Venturing, 19, 261-283.

Cassell, J. (1998). A framework for gesture generation and interpretation. In R. Cipolla \& A. Pentland (Eds.), Computer vision in human-machine interaction (pp. 191-215). Cambridge, UK: Cambridge University Press.

Chen, X. P., Yao, X., \& Kotha, S. (2009). Entrepreneur passion and preparedness in business plan presentations: A persuasion analysis of venture capitalists' funding decisions. The Academy of Management Journal, 52(1), 199-214.

Cienki, A. (1998). Metaphoric gestures and some of their relations to verbal metaphoric expressions. In J. P. Koenig (Ed.), Discourse and cognition: Bridging the gap (pp. 189-204), Stanford, CA: CSLI Publications.

Cienki, A. (2005). Image schemas and gesture. In B. Hampe (Ed.), From perception to meaning: Image schemas in cognitive linguistics (pp. 369-394). Berlin: Mouton de Gruyter.

Cienki, A. (2013) Conceptual metaphor theory in light of research on gesture with speech. Cognitive Semiotics, 5(1-2), 349-366.

Cienki, A. (2016). Cognitive linguistics, gesture studies and multi-modal communication. Cognitive Linguistics, 27(4), 603-618.

Cienki, A., \& Müller, C. (2008). Metaphor and gesture. Amsterdam: John Benjamins.

Clark, A. (1996). Being there: Putting brain, body and world together. Cambridge, MA: MIT Press.

Clark, C. (2008). The impact of entrepreneurs' oral "pitch" presentation skills on business angels' initial screening investment decisions. Venture Capital, 10(3), 257-279.

Clarke, J., \& Cornelissen, J. (2014). How language shapes thought: New vistas for entrepreneurship research. In J. R. Mitchell, R. K. Mitchell, \& B. Randolph-Seng (Eds.), Handbook of entrepreneurial cognition (pp. 383-397). Cheltenham, UK: Edward Elgar.

Clarke, J. S., Cornelissen, J. P., \& Healey, M. P. (2019). Actions speak louder than words: How figurative language and gesturing in entrepreneurial pitches influences investment judgements. Academy of Management Journal, 62(2), 335-360.

Congdon, E. L., Novack, M. A., \& Goldin-Meadow, S. (2018). Gesture in experimental studies: How videotape technology can advance psychological theory. Organizational Research Methods, 21(2), 489-499.

Corina, D. P., \& Gutierrez, E. (2016). Embodiment and American sign language sensory-motor influences in the recognition of American Sign Language. Gesture, 15(3), 291-305.

Cornelissen, J. (2005). Beyond compare: Metaphor in organization theory. Academy of Management Review, 30(4), 751-764.

Cornelissen, J., \& Clarke, J. (2010). Imagining and rationalizing opportunities: Inductive reasoning, and the creation and justification of new ventures. Academy of Management Review, 35(4), 539-557.

Cornelissen, J., Clarke, J., \& Cienki, A. (2012). Sensegiving in entrepreneurial contexts: The use of metaphors in speech and gesture to gain and sustain support for novel ventures. International Small Business Journal, 30(3), 213-241.

De Ruiter, J. P. (2000). The production of language and speech. In D. McNeill (Ed.), Language and gesture (pp. 284-311). Cambridge, UK: Cambridge University Press.

Efron, D. (1941). Gesture and environment: A tentative study of some of the spatio-temporal and linguistic aspects of the gestural behavior of eastern Jews and southern Italians in New York City, living under similar as well as different environmental conditions. King's Crown Press, New York.

Ekman, P., \& Friesen, W. (1969). The repertoire of nonverbal behavioral categories. Semiotica, 1(1), 49-98.

Forceville, C. J., \& Urios-Aparisi, E. (Eds.). (2009). Multimodal metaphor. New York, NY: Mouton de Gruyter.

Gallese, V., \& Lakoff, G. (2005). The brain's concepts: The role of the sensory-motor system in conceptual knowledge. Cognitive Neuropsychology, 22(3/4), 455-479.

Gibbs, R. W. (2006). Metaphor interpretation as embodied simulation. Mind and Language, 21(3), 434-458. 
Gibbs, R. W. (2008). The Cambridge handbook of metaphor and thought. Cambridge, UK: Cambridge University Press.

Goffman, I. (1981). Forms of talk. Philadelphia, PA: University of Pennsylvania Press.

Goodwin, C. (1979). The interactive construction of a sentence in natural conversation. In C. Psathas (Ed.), Everyday language: Studies in Ethnomethodology (pp. 97-121). New York, NY: Irvington Publishers

Goodwin, C. (1986). Between and within: Alternative sequential treatments of continuers and assessments. Human Studies, 9(2-3), 205-217.

Goodwin, C. (2000a). Action and embodiment within situated human interaction. Journal of Pragmatics, 32, $1489-522$.

Goodwin, C. (2000b). Gesture, aphasia and interaction. In D. McNeill (Ed.), Language and gesture: Window into thought and action (pp. 84-98). Cambridge, UK: Cambridge University Press.

Goodwin, C. (2003). Pointing as situated practice. In S. Kita (Ed.), Pointing: Where language, culture, and cognition meet. London: Lawrence Erlbaum.

Goodwin, M. H. (1980). Processes of mutual monitoring implicated in the production of description sequences. Sociological Inquiry, 50 (3-4), 303-317.

Goodwin, M. H., \& Goodwin, C. (1986). Gesture and coparticipation in activity of searching for a word. Semiotica, 62(1-2), 51-76.

Grady, J. (1997). Foundations of meaning: Primary metaphors and primary scenes. PhD dissertation, University of California, Berkeley.

Grady, J. (2005). Primary metaphors as inputs to conceptual integration. Journal of Pragmatics, 37(10), 1595-1614.

Green, E. M. (2017). The pragmatic function of pantomomic and lexical repertoires in a natural sign narrative. Gesture, 16(2), 329-363.

Gylfe, P., Franck, H., LeBaron, C., \& Mantere, S. (2016). Video methods in strategy research: Focusing on embodied cognition. Strategic Management Journal, 37, 133-148.

Hayashi, M. (2003). Language and the body as resources for collaborative action: A study of word searchers in Japanese conversation. Research on Language and Social Interaction, 36(2), 109-141.

Heath, C. (1986). Body movement and speech in medical interaction. Cambridge, UK: Cambridge University Press.

Heath, C. (2002). Demonstrative suffering: The gestural (re)embodiment of symptoms. Journal of Communication, 52(3), 597-616.

Heath, C., Hindmarsh, J., \& Luff, P. (2010). Video in qualitative research. London: Sage.

Hill, R. C., \& Levenhagen, M. (1995). Metaphors and mental models: Sensemaking and sensegiving in innovative and entrepreneurial activities. Journal of Management, 21(6), 1057-1074.

Hindmarsh, J., \& Heath, C. (2000). Embodied reference: A study of deixis in workplace interaction. Journal of Pragmatics, 32(12), 1855-1878.

Hindmarsh, J., \& Llewellyn, N. (2018). Video in sociomaterial investigations. Organizational Research Methods, 21(2), 412-437.

Hindmarsh, J., \& Pilnick, A. (2007). Knowing bodies at work: Embodiment and ephemeral teamwork in anaesthesia. Organization Studies, 28(9), 1395-1416.

Hockett, C. F., \& Ascher, R. (1964). The human revolution. Current Anthropology, 5, 135-147.

Huang, L., \& Pearce, J. L. (2015). Managing the unknowable: The effectiveness of early-stage investor gut feel in entrepreneurial investment decisions. Administrative Science Quarterly, 60(4), 634-670.

Iedema, R. (2007). On the multi-modality, materiality and contingency of organization discourse. Organization Studies, 28(6), 931-946.

Iverson, J. M., \& Thelen, E. (1999). Hand, mouth and brain: The dynamic emergence of speech and gesture. Journal of Consciousness Studies, 6, 19-40.

Jablin, F. M., \& Putnam, L. L. (2000). The new handbook of organizational communication: Advances in theory, research, and methods. London: Sage Publications. 
Jacobs, N., \& Garnham, A. (2007). The role of conversational hand gestures in a narrative task. Journal of Memory and Language, 56(2), 291-303.

Kaschak, M. P., Madden, C. J., Therriault, D. J., Yaxley, R. H., Aveyard, M., Blanchard, A. A., \& Zwaan, R. A. (2005). Perception of motion affects language processing. Cognition, 94, B79-B89.

Kendon, A. (1972). Some relationships between body motion and speech. In A. Siegman \& B. Pope (Eds.), Studies in dyadic communication (pp. 177-210). New York, NY: Pergamon Press.

Kendon, A. (1980). Gesticulation and speech: Two aspects of the process of utterance. In M. R. Kay (Ed.), The relationship between verbal and nonverbal behaviour (pp. 201-227). The Hague, Netherlands: Mouton.

Kendon, A. (1983). Gesture and speech: How they interact. In J. M. Wiemann \& R. P. Harrison (Eds.), Nonverbal interaction (pp. 13-45). Beverly Hills, CA: Sage Publications.

Kendon, A. (1994). Do gestures communicate: A review. Research on Language and Social Interaction, 27(3), 175-200.

Kendon, A. (1996). An agenda for gesture studies. Semiotic Review of Books, 7, 8-12.

Kendon, A. (1997). Gesture. Annual Review of Anthropology, 26, 109-128.

Kendon, A. (2004). Gesture: Visible action as utterance. Cambridge, UK: Cambridge University Press.

Kendon, A. (2007). On the origins of modern gesture studies. In S. D. Duncan, J. Cassell, \& E. T. Levy (Eds.), Gesture and the dynamic dimension of language (pp. 13-28). Amsterdam, Netherlands: John Benjamins.

Kendon, A. (2015). Gesture and sign: Utterance uses of visible bodily action. In K. Allen (Ed.), The Routledge handbook of linguistics (pp. 33-46). London and New York: Routledge, Taylor and Francis Group.

Kendon, A. (2017). Pragmatic functions of gestures: Some observations on the history of their study and their nature. Gestures, 16(2), 157-175.

Kress, G. (2011). Partnerships in research: Multimodality and ethnography. Qualitative Research, 11(3), 239-260.

Kress, G., \& van Leeuwen, T. (2001). Multimodal discourse: The modes and media of contemporary communication. London: Arnold.

Lakoff, G. (1987). The death of dead metaphor. Metaphor and Symbol, 2(2), 143-147.

Lakoff, G. (1993). The contemporary theory of metaphor. In A. Ortony (Ed.), Metaphor and thought (2nd ed., pp. 202-250). Cambridge, UK: Cambridge University Press.

Lakoff, G., \& Johnson, M. (1980). Metaphors we live by. Chicago, IL: University of Chicago Press.

Lakoff, G., \& Johnson, M. (1999). Philosophy in the flesh: The embodied mind and its challenge to western thought. New York, NY: Basic Books.

Langacker, R. W. (1987). Foundations of cognitive grammar: Theoretical prerequisites. Stanford, CA: Stanford University Press.

Langacker, R. (2008). Cognitive grammar. Oxford, UK: Oxford University Press.

LeBaron, C., Christianson, M. K., Garrett, L., \& Ilan, R. (2016). Coordinating flexible performance during everyday work: An ethnomethodological study of handoff routines. Organization Science, 27(3), 514-534.

LeBaron, C., Jarzabkowski, P., Pratt, M., \& Fetzer, G. (2017). An introduction to video methods in organizational research. Organizational Research Methods, 21(2), 239-260.

LeBaron, C., \& Streeck, J. (2000). Gestures, knowledge, and the world. In D. McNeill (Ed.), Gestures in action, language, and culture (pp. 118-140). Cambridge, UK: Cambridge University Press.

Llewellyn, N. (2014). "He probably thought we were students": Age norms and the exercise of visual judgment in service work. Organization Studies, 36(2), 153-173.

Llewellyn, N., \& Hindmarsh, J. (2010). Organization, interaction and practice: Studies in ethnomethodology and conversation analysis. Cambridge, UK: Cambridge University Press.

Lounsbury, M., \& Glynn, M. A. (2001). Cultural entrepreneurship: stories, legitimacy and the acquisition of resources. Strategic Management Journal, 22, 545-564.

Luff, P., \& Heath, C. (2012). Some "technical challenges" of video analysis: Social actions, objects, material realities and the problems of perspective. Qualitative Research, 12(3), 255-279. 
Mason, C. M., \& Harrison, R. T. (2003). "Auditioning for money”: What do technology investors look for at the initial screening stage. The Journal of Private Equity, 6(2), 29-42.

McNeill, D. (1985). So you think gestures are nonverbal? Psychological Review, 92, 350-371.

McNeill, D. (1992). Hand and mind: What gestures reveal about thought. Chicago, IL: University of Chicago Press.

McNeill, D. (2012). How language began: Gesture and speech in human evolution. Cambridge, UK: Cambridge University Press

McNeill, D., \& Levy, E. T. (1982). Conceptual representations in language activity and gesture. In R. Jarvella \& W. Klein (Eds.), Speech, place, and action (pp. 271-295). Chichester, UK: Wiley \& Sons.

Mitchell, J. R., Mitchell, R. K., \& Randolph-Seng, B. (2014). Handbook of entrepreneurial cognition. Cheltenham, UK: Edward Elgar Publishing.

Montredon, J., Amrani, A., Benoit-Barnet, M.-P., Chan You, E., Llorca, R., \& Peuteuil, N. (2008). Catchment, growth point, and spatial metaphor: Analyzing Derrida's oral discourse on deconstruction. In A. Cienki \& C. Muüller (Eds.), Metaphor and gesture (pp. 171-194). Amsterdam/Philadelphia: John Benjamins.

Muüller, C. (2008). What gestures reveal about the nature of metaphor. In A. Cienki \& C. Muüller (Eds.), Metaphor and gesture (pp. 219-248). Amsterdam: John Benjamins.

Napier, J. R. (1980). Hands. Princeton, NJ: Princeton University Press.

Navis, C., \& Glynn, M. A. (2010). How new market categories emerge: Temporal dynamics of legitimacy, identity, and entrepreneurship in satellite radio, 1990-2005. Administrative Science Quarterly, 55(3), 439-471.

Ng-Thow-Hing, V., Luo, P., \& Okita, S. (2010). Synchronized gesture and speech production for humanoid robots. In Proceedings of the IEEE/RSJ international conference on intelligent robots and systems (pp. 4617-4624). New York, NY: IEEE.

Ozcaliskan, S., \& Goldin-Meadow, S. (2005). Gesture is at the cutting edge of early language development. Cognition, 96(3), B101-B113.

Pollack, J. M., Rutherford, M. W., \& Nagy, B. (2012). Preparedness and cognitive legitimacy as antecedents to new venture funding in televised business pitches. Entrepreneurship Theory and Practice, 36, 915-939.

Pragglejaz Group. (2007). MIP: A method for identifying metaphorically-used words in discourse. Metaphor and Symbol, 22(1), 1-39.

Quinn, N. (2008). Metaphoric gestures and cultural analysis. In A. Cienki \& C. Muüller (Eds.), Metaphor and gesture (pp. 253-257). Amsterdam: John Benjamins.

Rimé, B., \& Schiaratura, L. (1991). Gesture and speech. In R. S. Feldman \& B. Rimé (Eds.), Fundamentals of nonverbal behavior (pp. 239-281). New York, NY: Cambridge University Press.

Rogers, W. T. (1978). The contribution of kinesic illustrators toward the comprehension of verbal behaviors within utterances. Human Communication Research, 5, 54-62.

Sacks, H. (1992). Lectures on conversation: Volumes I and II (G. Jefferson, Ed.). Oxford, UK: Blackwell.

Sacks, H., Schegloff, E. A., \& Jefferson, G. (1974). A simplest systematics for the organization of turn-taking for conversation. Language, 50, 696-735.

Sanjeevan, T., Mainela-Arnold, E., Alibali, M. W., \& Evans, J. L. (2016). The temporal relationship between speech and manual communicative gesture in children with specific language impairment. Gesture, 15(3), 321-339.

Schegloff, E. A. (1968). Sequencing in conversational openings. American Anthropologist 70(6), 1075-1095.

Schegloff, E. A. (1984). On some gestures relation to speech. In J. M. Atkinson \& J. Heritage (Eds.), Structures of social action: Studies in conversation analysis (pp. 266-296). Cambridge, UK: Cambridge University Press.

Schegloff, E. A. (1988). Goffman and the analysis of conversation. In P. Drew \& A. Wootton (Eds.), Erving Goffman: Exploring the interaction order (pp. 89-135). Cambridge, UK: Polity Press. 
Schegloff, E. A. (1995). Introduction. In H. Sacks, Lectures on conversation: Volumes I and II. Oxford, UK: Blackwell.

Sidnell, J. (2005). Gesture in the pursuit and display of recognition: A Caribbean case study. Semiotica, 156, 55-87.

Speer, S. A., \& Hutchby, I. (2003). From ethics to analytics: Aspects of participants' orientations to the presence and relevance of recording devices. Sociology, 37(2), 315-337.

Streeck, J. (1993). Gesture as communication: Its coordination with gaze and speech. Communication Monographs, 60(4), 275-299.

Streeck, J. (1994). Gesture as communication II: The audience as co-author. Research on Language and Social Interaction, 27(3), 239-267.

Streeck, J. (2002). The body and its gestures. Gesture, 2(1), 19-44.

Streeck, J. (2008a). Gesture in political communication: A case study of the democratic presidential candidates during the 2004 primary campaign. Research on Language and Social Interaction, 41(2), 154-186.

Streeck, J. (2008b). Metaphor and gesture: A view from microanalysis of interaction. In A. Cienki \& C. Muüller (Eds.), Metaphor and gesture (pp. 259-264). Amsterdam: John Benjamins.

Streeck, J., Goodwin, C., \& LeBaron, C. (2011). Embodied interaction: Language and body in the material world. Cambridge, UK: Cambridge University Press.

Streeck, J., \& Hartge, U. (1992). Previews: Gestures at the transition place. In P. Auer \& A. Di Luzio (Eds.), The contextualization of language (pp. 135-157). Philadelphia, PA: John Benjamin.

Sweetser, E. (1998). Regular metaphoricity in gesture: Bodily-based models of speech interaction. Actes du 16e Congrès International des Linguistes (CD-ROM), Elsevier.

Talmy, L. (2000). Towards a cognitive semantics: Vol 1. Conceptual structuring systems. Cambridge, MA: MIT Press.

Tellier, M. (2008). The effect of gestures on second language memorization by young children. Gesture, $8(2)$, 219-235.

Tylor, E. B. (1865). Researches into the early history of mankind and the development of civilization. London: John Murray.

Van Werven, R., Bouwmeester, O., \& Cornelissen, J. P. (2015). The power of arguments: How entrepreneurs convince stakeholders of the legitimate distinctiveness of their ventures. Journal of Business Venturing, 30(4), 616-631.

Wenzel, M., \& Koch, J. (2018). Strategy as staged performance: A critical discursive perspective on keynote speeches as a genre of strategic communication. Strategic Management Journal, 39(3), 639-663.

Whittington, R., Yakis-Douglas, B., \& Ahn, K. (2016). Cheap talk? Strategy presentations as a form of chief executive officer impression management. Strategic Management Journal, 37(12), 2413-2424.

\section{Author Biographies}

Jean S. Clarke is a professor of entrepreneurship and organization at Emlyon Business School, France. She received her $\mathrm{PhD}$ from the University of Leeds, UK. Her research explores how language and bodily displays are used in entrepreneurial communication as a means to develop legitimacy and access resources.

Nick Llewellyn is professor of organization studies and ProDean Faculty at Warwick Business School, UK. Drawing on resources from ethnomethodology and conversation analysis, his work addresses the social and interactional organization of work practices. 
Joep Cornelissen is a professor of corporate communication and management at the Rotterdam School of Management, Erasmus University. He received his PhD from the Manchester Metropolitan University. He has interests in sensemaking, communication, qualitative research, and theory development.

Rowena Viney is a lecturer in medical education at University College London Medical School. Her background is in sociolinguistics, and her research interests include conversation analysis, multimodal interaction, medical communication, education, and assessment. 